\title{
Performance of Møller-Plesset second-order perturbation theory and density functional theory in predicting the interaction between stannylenes and aromatic molecules
}

\author{
Piotr Matczak • Sławomir Wojtulewski
}

Received: 31 October 2014 / Accepted: 26 January 2015 / Published online: 13 February 2015

(C) The Author(s) 2015. This article is published with open access at Springerlink.com

\begin{abstract}
The performances of Møller-Plesset second-order perturbation theory (MP2) and density functional theory (DFT) have been assessed for the purposes of investigating the interaction between stannylenes and aromatic molecules. The complexes between $\mathrm{SnX}_{2}$ (where $\mathrm{X}=\mathrm{H}, \mathrm{F}, \mathrm{Cl}, \mathrm{Br}$, and I) and benzene or pyridine are considered. Structural and energetic properties of such complexes are calculated using six MP2-type and 14 DFT methods. The assessment of the above-mentioned methods is based on the comparison of the structures and interaction energies predicted by these methods with reference computational data. A very detailed analysis of the performances of the MP2-type and DFT methods is carried out for two complexes, namely $\mathrm{SnH}_{2}$-benzene and $\mathrm{SnH}_{2}$ pyridine. Of the MP2-type methods, the reference structure of $\mathrm{SnH}_{2}$-benzene is reproduced best by SOS-MP2, whereas SCS-MP2 is capable of mimicking the reference structure of $\mathrm{SnH}_{2}$-pyridine with the greatest accuracy. The latter method performs best in predicting the interaction energy between $\mathrm{SnH}_{2}$ and benzene or pyridine. Among the DFT methods, $\omega \mathrm{B} 97 \mathrm{X}$ provides the structures and interaction energies of the $\mathrm{SnH}_{2}$-benzene and $\mathrm{SnH}_{2}$-pyridine complexes with good accuracy. However, this density functional is not as effective in reproducing the reference data for the two complexes as the best performing MP2-type methods. Next, the DFT methods
\end{abstract}

Electronic supplementary material The online version of this article (doi:10.1007/s00894-015-2589-1) contains supplementary material, which is available to authorized users.

P. Matczak $(\bowtie)$

Department of Theoretical and Structural Chemistry, Faculty of

Chemistry, University of Łódź, Pomorska 163/165,

90-236 Lodz, Poland

e-mail: p.a.matczak@gmail.com

S. Wojtulewski

Institute of Chemistry, University of Białystok, Hurtowa 1,

15-399 Bialystok, Poland are evaluated using the full test set of $\mathrm{SnX}_{2}$-benzene and $\mathrm{SnX}_{2}$-pyridine complexes. It is found that the rangeseparated hybrid or dispersion-corrected density functionals should be used for describing the interaction in such complexes with reasonable accuracy.

Keywords Benchmarking $\cdot$ MP2 $\cdot$ DFT · Benzene · Pyridine $\cdot$ Stannylene

\section{Introduction}

Quantum-chemical modeling of organometallic systems and inorganic systems containing metal atoms is a challenging task because of the large number of electrons and strong electron correlation effects occurring in metal atoms. In recent years the vast majority of computational studies of these systems were performed using density functional theory (DFT) $[1,2]$ and such a widespread adoption of DFT methods stemmed from their excellent ratio of computational cost to accuracy. DFT methods are able to include a large fraction of electron correlation and their computational cost scales favorably with the size of molecular systems (formally between $\mathrm{O}\left(N^{3}\right)$ and $\mathrm{O}\left(N^{4}\right)$, where $N$ is proportional to system size). Unfortunately, these methods also have their weaknesses. DFT methods suffer from the spurious self-interaction of electrons, which results in too much electron delocalization and too low total energies [3, 4]. Another weakness is their inability to describe long-range electron correlations that are responsible for dispersive forces [1]. However, the constant development in DFT has led to some progress in overcoming, at least partially, these weaknesses. For instance, some reduction in the self-interaction can be provided by the inclusion of either the long-range correction or a substantial, global portion of 
exact exchange [3], whereas the lack of dispersion can be compensated by various empirical corrections [5]. Because DFT is in fact a family of methods (in other words, density functionals), and each of them presents an approximate approach to the unknown exact density functional, the approximations used in a given DFT method affect its accuracy in modeling a specific molecular system. Therefore, each density functional requires testing prior to its application and many studies evaluating the performance of density functionals for various organometallic systems and inorganic systems containing metal atoms have been published, e.g., [6-10] to mention only a few of the most recent.

Before the advent of the immense popularity of DFT methods, organometallic systems and inorganic systems containing metal atoms were usually investigated using MøllerPlesset second-order perturbation theory (MP2) [11], that is the simplest and most economical method among postHartree-Fock wave function-based theories (WFT). In contrast to DFT, the MP2 method is free from the spurious selfinteraction of electrons and naturally takes dispersion into account. However, the MP2 dispersion may exhibit a deficiency when the interaction between fragments of a molecular system is calculated. The resulting interaction energy may be overestimated noticeably because the MP2 method makes use of the uncoupled Hartree-Fock dispersion energy that lacks the repulsive intramolecular correlation correction $[12,13]$. Many attempts to remove such an overestimation were made in recent years [14-18] and one of the most successful solutions is, perhaps, the spin-component scaling (SCS) [14] that introduces separate scaling coefficients for MP2 correlation energy contributions coming from parallel- and antiparallelspin pairs of electrons. These scaling coefficients can be either deduced from theory [19] or obtained from parametrization against some benchmark data $[14,20]$. Therefore, SCS schemes can be tailored to modeling a specific kind of systems $[21,22]$. Although the conventional MP2 method is the most economical post-Hartree-Fock method, its computational cost scales as $O\left(N^{5}\right)$, hence it is much higher than that of DFT methods. The resolution of the identity (RI) $[23,24]$ is a widely used technique making the MP2 method more computationally affordable. It leads to computational savings amounting to 1-2 orders of magnitude compared to conventional MP2 calculations. The application of the conventional MP2 method to organometallic systems and inorganic systems containing metal atoms revealed severe inaccuracies in the description of $3 d$ transition metal complexes [25]. In such cases the aforementioned modifications of the conventional MP2 method may provide an improvement in accuracy and the SCS-MP2 variant indeed performs better than MP2 for complexes with transition metals [26, 27].

The progress made in the last decade in the development of MP2 variants and density functionals has encouraged us to inspect how accurately such new methods are able to model systems composed of a stannylene and an aromatic molecule. Stannylenes are singlet species of divalent tin with a formal $5 s^{2} 5 p^{2}$ valence electron configuration [28]. In the ground state they possess an electron lone pair and a vacant $p$-orbital on the $\mathrm{Sn}$ atom. The vacant $\mathrm{p}$-orbital is responsible for their high reactivity whereas the lone pair is rather inert due to its high s-character [29]. Many stannylenes can be easily obtained in laboratory conditions and some of them (e.g., dihalogenated stannylenes) are stable enough to be handled under ambient conditions [29]. From the practical point of view, stannylenes have found several important applications. For instance, they can act as active single-site catalysts for the living polymerization of lactide [30,31]. Stannylenes have also been investigated theoretically, using mostly DFT methods [32-38] and rarely at the MP2 level of theory $[33,39]$. Recently, the interaction between stannylenes and aromatic rings has attracted much interest [40], although such an interaction was detected experimentally some time before, e.g., [41]. In the theoretical studies devoted to this subject $[42,43]$ some density functionals such as B3LYP and PBE, also combined with a dispersion correction, were employed. However, it is not clear whether the B3LYP functional, which is without any doubt the most popular DFT method, provides a sufficiently accurate description of systems containing stannylenes and aromatic molecules and which DFT method would be in general most appropriate for investigating such systems. In this work, we would like to assess quantitatively the performance of selected MP2 variants and density functionals belonging to several DFT generations for predicting geometrical and energetic parameters of computational model systems that include stannylenes $\mathrm{SnX}_{2}$ (where $\mathrm{X}=\mathrm{H}, \mathrm{F}, \mathrm{Cl}, \mathrm{Br}, \mathrm{I}$ ) in their $\pi$ complexes with benzene and in their $\sigma$-complexes with pyridine. On the one hand, the singlet spin multiplicity of stannylenes simplifies these model systems but on the other hand providing the accurate theoretical description of interactions with aromatic molecules may be a demanding task [44-46].

\section{Computational details}

In the first part of this work we focus on the performance of the conventional MP2 method and its five modifications, namely SCS-MP2 [14], SOS-MP2 [20], FE2-MP2 [47], SCS(MI)-MP2 [48], and S2-MP2 [19]. The results calculated using these six MP2-type methods were compared with the results obtained from CCSD [49] and $\operatorname{CCSD}(\mathrm{T})$ [49]. The CCSD method was recently used for providing reference geometries of non-covalently interacting molecular complexes $[50,51]$. Reference interaction energies between stannylenes and aromatic molecules in the investigated $\pi$ - and $\sigma$ complexes were calculated using $\operatorname{CCSD}(\mathrm{T})$ because this method is commonly considered to be the "golden standard" for 
obtaining reference results for systems with intermolecular interactions [52]. All the MP2-type methods and $\operatorname{CCSD}(\mathrm{T})$ employed the RI technique and the frozen core approximation to calculate the electron correlation energy. TURBOMOLE 6.3.1 [53] was used to carry out the calculations involving the MP2-type and CCSD(T) methods. The CCSD optimizations were performed with GAUSSIAN 09 C.01 [54] because analytic gradients were available for CCSD in this software. The frozen core approximation was also used in the CCSD calculations.

In the second part of the work a set of density functionals belonging to various DFT generations is tested. This set includes both representatives of older DFT generations, such as the generalized gradient approximation (GGA) and global hybrids $(\mathrm{GH})$, and some modern density functionals such as those making use of the local kinetic energy density (that is, the meta-GGA generation) and range-separated hybrids (RSH). The generations of density functionals, together with their representatives considered in this work, are listed in Table 1.

Four older density functionals (BLYP, BP86, B3LYP, and B98) were taken into account because they are still widely used in the investigations of organotin molecules [55-57], including stannylenes [32, 33, 36-38], and, what is more important, we wanted to verify whether the addition of a DFT-D dispersion correction improved their performance. We employed the D2 dispersion correction [58] that is classified as the so-called simple $C_{6}$ correction [5]. This correction was parametrized only for selected density functionals. Grimme determined the D2 parameters appropriate for BP86, BLYP, B3LYP, and TPSS [58], whereas the D2-type correction for the $\omega \mathrm{B} 97 \mathrm{X}$ functional was proposed by Chai and HeadGordon [59]. In this work the aforementioned functionals combined with the $\mathrm{D} 2$ correction will be denoted by the suffix "-D". We decided to use the B97-D density functional [58] as the dispersion-corrected version of $\mathrm{B} 98$, although the presence of the dispersion correction is not the only difference between these two functionals. The DFT calculations were performed with GAUSSIAN 09 C.01 (for BP86, BLYP, B3LYP, B98, B97-D, $\omega$ B97X, and $\omega$ B97X-D), GAUSSIAN 09 D.01 [60]

Table 1 Generations of density functionals and their representatives considered in this work

\begin{tabular}{ll}
\hline Generation & Representative \\
\hline GGA & BP86 [92, 93], BLYP [80, 92] \\
meta-GGA & TPSS [94] \\
GH GGA & B3LYP [95, 96], B98 [97] \\
GH meta-GGA & TPSSh [98] \\
RSH GGA & $\omega$ B97X [59] \\
RSH meta-GGA & M11 [99] \\
\hline
\end{tabular}

(for BP86-D, BLYP-D, B3LYP-D, and M11) and TURBOMOLE 6.3.1 (for TPSS, TPSS-D, and TPSSh).

Both the WFT and the DFT methods were combined with two types of triple- $\zeta$ valence basis sets, namely cc-pVTZ [61], that belongs to the family of basis sets proposed by Dunning and co-workers, and def2-TZVP [62], that in turn is a representative of the family developed by Ahlrichs and co-workers. The def2-TZVP basis set assigns small-core relativistic pseudopotentials (covering 28 core electrons) to the Sn and I atoms in the $\mathrm{SnX}_{2}$ stannylenes. The variant of def2-TVZP with double polarization functions designed for correlated calculations (that is, def2-TZVPP) was used in the WFT calculations. In the case of the cc-pVTZ basis set its extension developed by Peterson [63] and denoted by cc-pVTZ-PP was employed for Sn and I. In the cc-pVTZ-PP basis set the core electrons of $\mathrm{Sn}$ and I are described by the pseudopotentials that are very similar to those adopted in def2-TZVP. Additionally, cc-pVTZ and def2-TZVP in their diffuse-augmented versions, aug-cc-pVTZ [61] and def2-TZVPD [64], respectively, were also used.

The optimized geometries of the $\mathrm{SnX}_{2}$-benzene $\pi$ complexes (where $\mathrm{X}=\mathrm{H}, \mathrm{F}, \mathrm{Cl}, \mathrm{Br}, \mathrm{I}$ ) and of the $\mathrm{SnX}_{2}$-pyridine $\sigma$-complexes were confirmed to be true local minima with the aid of vibrational frequency analysis. The interaction energy between $\mathrm{SnX}_{2}$ and benzene/pyridine in the optimized complexes was calculated in the supermolecular fashion. The sum of the total energies of isolated $\mathrm{SnX}_{2}$ and benzene/ pyridine in their geometries found in the $\mathrm{SnX}_{2}$-benzene/ $\mathrm{SnX}_{2}$-pyridine complexes was subtracted from the total energy of these complexes. In order to remove the basis-set superposition error (BSSE) from the values of interaction energy, the counterpoise correction proposed by Boys and Bernardi [65] was employed.

The comparison of the $\mathrm{SnX}_{2}$-benzene or $\mathrm{SnX}_{2}$-pyridine structures optimized by different methods was made using the minimized root-mean-square value of the residual distances (RMSD) between the corresponding atoms belonging to these structures. The values of RMSD were computed with HYPERCHEM 8.0 [66].

\section{Results and discussion}

Assessment of MP2-type methods

We start with assessing the performance of six MP2-type methods in predicting the geometries of two stannylenearomatic molecule complexes. The simplest possible stannylene, $\mathrm{SnH}_{2}$, was selected to form its complexes with benzene and with pyridine. As no experimental characterization of the geometries of these complexes exists, we used the geometries optimized with the CCSD method as references for the assessment of the MP2-type methods. The very high 
computational cost of the CCSD optimizations was the reason to focus here only on the two complexes. The assessment of the MP2-type methods was performed separately for each of four basis sets mentioned in the previous section and the same basis set was combined both with MP2-type methods and with CCSD in order to optimize the geometries of the complexes and then to compare them.

Before we present the quantitative results of the assessment of the geometries optimized by six MP2-type methods, we give our attention to the $\mathrm{SnH}_{2}$-benzene and $\mathrm{SnH}_{2}$-pyridine complexes and describe roughly their structure itself. The optimization of the geometry of the system composed of $\mathrm{SnH}_{2}$ and benzene leads to a complex in which the $\mathrm{Sn}$ atom of $\mathrm{SnH}_{2}$ is positioned over one of the $\mathrm{C}$ atoms of benzene and two $\mathrm{H}$ atoms of the stannylene molecule are pointed to the outside of the benzene ring. The molecular plane of $\mathrm{SnH}_{2}$ is approximately parallel to the molecular plane of benzene (see Fig. 1, these two planes are colored red and yellow, respectively). In others words, the unfilled p-orbital of the $\mathrm{Sn}$ atom is pointed at the $\pi$-electron sextet and, therefore, the resulting complex can be termed the $\pi$-complex. As for the $\mathrm{SnH}_{2}$-pyridine complex, the stannylene molecule could interact with either the $\pi$-electron sextet or the lone electron pair of nitrogen. We investigated the second case and then the unfilled porbital of the $\mathrm{Sn}$ atom in $\mathrm{SnH}_{2}$ approached the lone electron pair on the $\mathrm{N}$ atom of pyridine. More specifically, the plane of the $\mathrm{SnH}_{2}$ molecule was arranged perpendicularly to the plane of pyridine (see Fig. 1, these two planes are marked red and yellow, respectively). The optimized geometries of both the $\pi$ complex of $\mathrm{SnH}_{2}$ with benzene and the $\sigma$-complex of $\mathrm{SnH}_{2}$ with pyridine exhibited the $\mathrm{C}_{\mathrm{s}}$ point group symmetry. To conclude, $\mathrm{SnH}_{2}$-benzene and $\mathrm{SnH}_{2}$-pyridine will be considered here to be prototype systems for the $\pi$ - and $\sigma$-complexations of stannylenes by aromatic molecules.

Let us now turn our attention to the results of the assessment of six MP2-type methods for predicting the geometries of $\mathrm{SnH}_{2}$-benzene and $\mathrm{SnH}_{2}$-pyridine. The assessment was performed separately for the geometry of both complexes and the quantitative comparison of the geometries optimized by the MP2-type methods with the geometries obtained from CCSD was based on RMSD. The values of RMSD express quantitatively the deviation of the geometries optimized by the MP2-type methods from the CCSD geometries. The lower the value of RMSD for a given MP2-type method is obtained, the smaller the difference in the geometries yielded by this method and by CCSD occurs. The values of RMSD for $\mathrm{SnH}_{2}-$ benzene and $\mathrm{SnH}_{2}$-pyridine are presented graphically in Fig. 2. As can be deduced from the left-hand plot in this figure, the SOS-MP2 method yields the lowest values of RMSD for the $\pi$-complex. These values are below $0.02 \AA$ for all four basis sets considered. Larger RMSD values are produced by SCS-MP2 and SCS(MI)-MP2 but the order of these two methods with respect to their RMSD values is dependent on the basis set applied. The $\mathrm{SnH}_{2}$-benzene complex optimized by the conventional MP2 method is in the worst agreement with the CCSD geometry. Regarding how the choice of basis set affects the $\mathrm{SnH}_{2}$-benzene geometry, it can be seen that the addition of the set of diffuse functions to the cc-pVTZ basis set decreases the values of RMSD. On the other hand, the application of the def2-TZVPPD basis set does not always improve the reproduction of the $\pi$-complex geometry as compared to the result obtained with the def2-TZVPP basis set. It might result from the fact that the set of diffuse functions in def2TZVPPD was primarily designed to achieve high accuracy for molecular polarizabilities [64]. The geometry of the $\mathrm{SnH}_{2}$ pyridine complex is reproduced best by the SCS-MP2 method. This method is followed by SOS-MP2, irrespective of the basis set employed. The effect of diffuse functions on the geometry of the $\sigma$-complex is irregular: the addition of the 'aug' set to cc-pVTZ increases the value of RMSD for SCSMP2 and SOS-MP2 but the remaining MP2-type methods exhibit a decrease in their RMSD on going from cc-pVTZ to aug-cc-pVTZ.

It is noteworthy that the values of RMSD for $\mathrm{SnH}_{2}$-pyridine are generally lower than those for $\mathrm{SnH}_{2}$-benzene. It indicates that for the $\sigma$-complexation the MP2-type methods tend to provide a structural description that is more consistent with that of CCSD than is observed for the $\pi$-complexation. For
Fig. $1 \pi$-Complex of $\mathrm{SnH}_{2}$ with benzene (left) and $\sigma$-complex of $\mathrm{SnH}_{2}$ with pyridine (right)
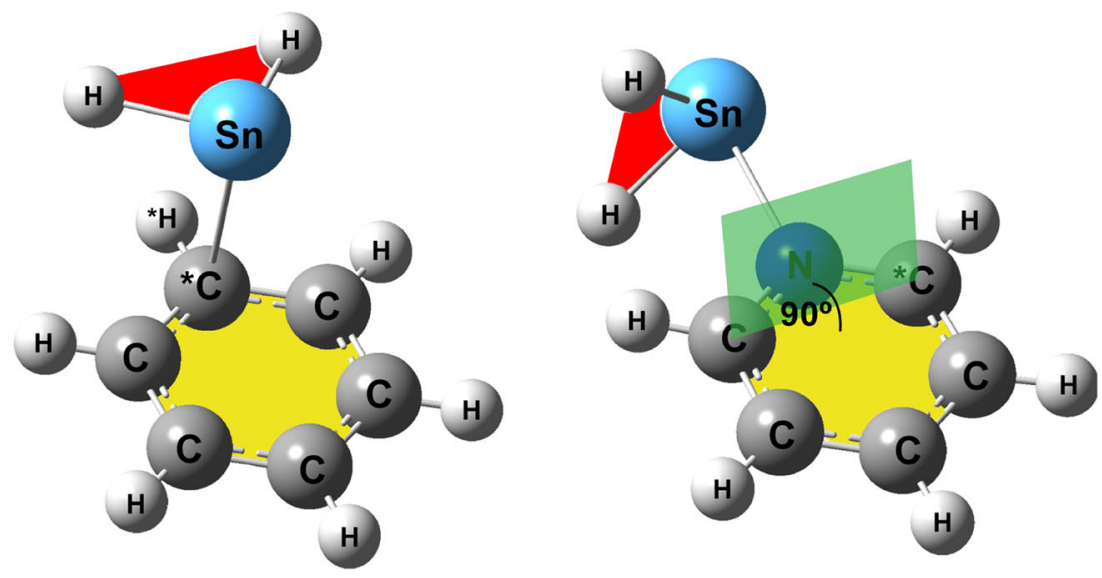

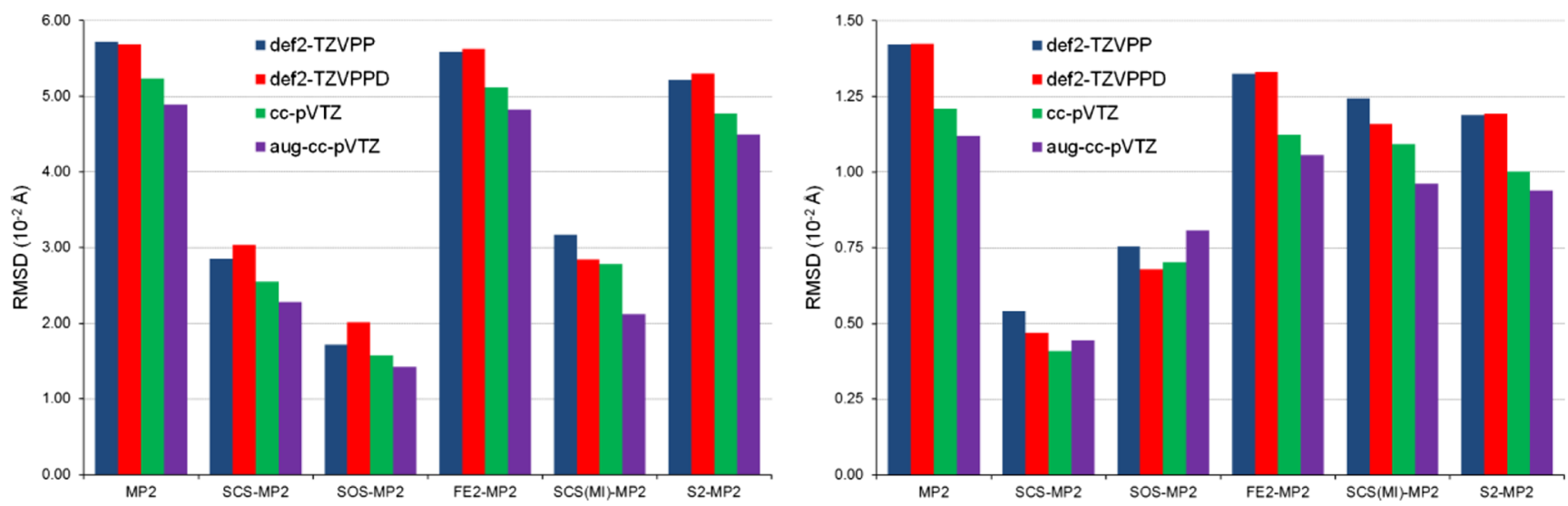

Fig. 2 RMSD for the $\pi$-complex of $\mathrm{SnH}_{2}$ with benzene (left) and the $\sigma$-complex of $\mathrm{SnH}_{2}$ with pyridine (right) obtained by MP2 and its variants in combination with four basis sets

both types of complexation the MP2, FE2-MP2, and S2-MP2 combined with all four basis sets systematically yield structures that differ from the CCSD structures significantly. Of all six MP2-type methods applied here, the conventional one shows the largest values of RMSD, hence the use of any of the five SCS schemes considered in this work leads to a reduction in the RMSD values for both types of complexation. The improvement in geometry predicted by SCS-MP2 over that optimized by MP2 was previously reported for various systems containing gold $[67,68]$. It was also suggested only recently that SOS-MP2 seems to be superior to MP2 in calculating geometrical parameters for the complex of benzene with tetracyanoethylene [69]. The best performance of the SCSMP2 method in reproducing the structure of $\mathrm{SnH}_{2}$-pyridine is in line with our previous findings on the robustness of this method for the structural characterization of intermolecular $\mathrm{N} \rightarrow$ Sn coordination in trimethyltin cyanide [70].

The results of the assessment performed using RMSD can also be confirmed by the deviations in the values of the key structural parameters characterizing the $\pi$ - and $\sigma$-complexations. Three structural parameters, namely one interatomic distance $(d)$ and two angles $\left(a_{1}\right.$ and $\left.a_{2}\right)$, were selected. In consequence of such a selection, the $\pi$-complexation in $\mathrm{SnH}_{2}$-benzene is described by the $\mathrm{Sn}-\mathrm{C}^{*}$ distance, the $\mathrm{Sn}$ $\mathrm{C}^{*}-\mathrm{H}^{*}$ valence angle and the angle between the molecular plane of $\mathrm{SnH}_{2}$ and the molecular plane of the benzene ring (see Fig. 1, the atoms marked with an asterisk are specified in the figure). In the case of the $\mathrm{SnH}_{2}$-pyridine complex, $d$ denotes the $\mathrm{Sn}-\mathrm{N}$ distance, $a_{1}$ is the $\mathrm{Sn}-\mathrm{N}-\mathrm{C}^{*}$ valence angle and $a_{2}$ specifies the angle between the molecular plane of $\mathrm{SnH}_{2}$ and the plane perpendicular to the pyridine ring (a fragment of the perpendicular plane is colored green in the right-hand panel in Fig. 1). The values of the three structural parameters for the $\mathrm{SnH}_{2}$-benzene and $\mathrm{SnH}_{2}$-pyridine complexes optimized using six MP2-type methods combined with the aug-ccpVTZ basis set are listed in Table 2 (additional results obtained using the remaining three basis sets can be found in
Tables S1-S3, see Electronic supplementary material). This table also shows the deviations in the values of the parameters calculated using the MP2-type methods from the reference values computed from the CCSD/aug-cc-pVTZ optimizations. The values of the deviations firmly support the results of the assessment performed using RMSD. Moreover, it is apparent that the conventional MP2 method shortens the $d$ distance in both complexes significantly, while the SOSMP2 method overestimates it slightly. The values of the $a_{1}$ angle for the $\pi$-complex $\left(a_{1}>90^{\circ}\right)$ indicate that the $\mathrm{Sn}$ atom is not positioned exactly over one of the $\mathrm{C}$ atoms of benzene but it is shifted toward the center of the benzene ring minimally.

Table 2 Selected geometrical parameters $\left(d, a_{1}\right.$, and $\left.a_{2}\right)$ for the $\pi$ complex of $\mathrm{SnH}_{2}$ with benzene and for the $\sigma$-complex of $\mathrm{SnH}_{2}$ with pyridine optimized by six MP2-type methods and CCSD in combination with the aug-cc-pVTZ basis set

\begin{tabular}{|c|c|c|c|c|c|c|}
\hline \multirow[t]{2}{*}{ Method } & \multicolumn{3}{|c|}{$\mathrm{SnH}_{2}$-benzene } & \multicolumn{3}{|c|}{$\mathrm{SnH}_{2}$-pyridine } \\
\hline & $d$ & $a_{1}$ & $a_{2}$ & $d$ & $a_{1}$ & $a_{2}$ \\
\hline MP2 & $\begin{array}{l}2.721 \\
(-0.105)\end{array}$ & $\begin{array}{l}92.39 \\
(2.82)\end{array}$ & $\begin{array}{l}10.17 \\
(-4.11)\end{array}$ & $\begin{array}{l}2.313 \\
(-0.022)\end{array}$ & $\begin{array}{l}119.79 \\
(-0.33)\end{array}$ & $\begin{array}{l}5.71 \\
(0.10)\end{array}$ \\
\hline SCS-MP2 & $\begin{array}{l}2.790 \\
(-0.036)\end{array}$ & $\begin{array}{l}91.40 \\
(1.84)\end{array}$ & $\begin{array}{l}11.94 \\
(-2.34)\end{array}$ & $\begin{array}{l}2.336 \\
(0.001)\end{array}$ & $\begin{array}{l}120.06 \\
(-0.06)\end{array}$ & $\begin{array}{l}5.74 \\
(0.14)\end{array}$ \\
\hline SOS-MP2 & $\begin{array}{l}2.829 \\
(0.003)\end{array}$ & $\begin{array}{l}90.90 \\
(1.33)\end{array}$ & $\begin{array}{l}12.80 \\
(-1.47)\end{array}$ & $\begin{array}{l}2.347 \\
(0.012)\end{array}$ & $\begin{array}{l}120.19 \\
(0.07)\end{array}$ & $\begin{array}{l}5.77 \\
(0.16)\end{array}$ \\
\hline FE2-MP2 & $\begin{array}{l}2.726 \\
(-0.100)\end{array}$ & $\begin{array}{l}92.44 \\
(2.87)\end{array}$ & $\begin{array}{l}10.23 \\
(-4.04)\end{array}$ & $\begin{array}{l}2.316 \\
(-0.019)\end{array}$ & $\begin{array}{l}119.87 \\
(-0.26)\end{array}$ & $\begin{array}{l}5.85 \\
(0.24)\end{array}$ \\
\hline SCS(MI)-MP2 & $\begin{array}{l}2.771 \\
(-0.055)\end{array}$ & $\begin{array}{l}90.79 \\
(1.23)\end{array}$ & $\begin{array}{l}11.99 \\
(-2.29)\end{array}$ & $\begin{array}{l}2.325 \\
(-0.010)\end{array}$ & $\begin{array}{l}119.62 \\
(-0.50)\end{array}$ & $\begin{array}{l}4.83 \\
(-0.78)\end{array}$ \\
\hline S2-MP2 & $\begin{array}{l}2.734 \\
(-0.092)\end{array}$ & $\begin{array}{l}92.32 \\
(2.75)\end{array}$ & $\begin{array}{l}10.46 \\
(-3.82)\end{array}$ & $\begin{array}{l}2.318 \\
(-0.017)\end{array}$ & $\begin{array}{l}119.90 \\
(-0.22)\end{array}$ & $\begin{array}{l}5.86 \\
(0.25)\end{array}$ \\
\hline CCSD & 2.826 & 89.57 & 14.27 & 2.335 & 120.12 & 5.61 \\
\hline
\end{tabular}

For the MP2-type methods the deviations of the three parameters from the values calculated using CCSD/aug-cc-pVTZ are shown in parentheses

Distances in $\AA$, angles in ${ }^{\circ}$. Each deviation is calculated as the difference between a value obtained from a given MP2-type method and the corresponding reference result 
For the $\mathrm{SnH}_{2}$-benzene and $\mathrm{SnH}_{2}$-pyridine complexes optimized by six MP2-type methods, the interaction energy between $\mathrm{SnH}_{2}$ and benzene/pyridine was calculated using the same methodologies as those applied to the optimizations. Both uncorrected $\left(E_{\text {int }}\right)$ and counterpoise-corrected $\left(E_{\text {int }}^{\mathrm{CP}}\right)$ interaction energies were considered. In order to provide the reference values of $E_{\text {int }}$ and $E_{\text {int }}^{\mathrm{CP}}$ for each basis set, the $\operatorname{CCSD}(\mathrm{T})$ calculations were carried out for the complexes optimized at the CCSD level of theory. The values of $E_{\text {int }}$ and $E_{\text {int }}^{\mathrm{CP}}$ calculated using the aug-cc-pVTZ basis set are presented in Table 3 (additional results obtained using the remaining three basis sets can be found in Tables S4-S6, see Electronic supplementary material). The deviations in the interaction energies predicted by the MP2-type methods from the reference $\operatorname{CCSD}(\mathrm{T})$ values are also tabulated. Perusing Table 3 leads to several findings. First, the interaction in the $\sigma$-complex is about twice as strong as that in the $\pi$-complex. Second, the comparison of $E_{\text {int }}$ with $E_{\text {int }}^{\mathrm{CP}}$ reveals that the counterpoise correction for the BSSE in the interaction energies for both complexes is large and its magnitude can reach several kcal mol${ }^{-1}$ (the maximal correction of $4.90 \mathrm{kcal} \mathrm{mol}^{-1}$ was found for the $\sigma$-complex at the FE2-MP2/aug-cc-pVTZ level of theory). The addition of the set of diffuse functions to both def2TZVPP and cc-pVTZ results in higher values of the counterpoise correction for the BSSE, although such an addition formally increases the completeness of these basis sets and a decrease in the BSSE could actually be expected. However, when the diffuse functions of def2-TZVPPD and aug-cc$\mathrm{pVTZ}$ are centered on one molecular moiety, they overlap to a certain extent the centers on the other moiety (e.g., in the

Table $3 E_{\text {int }}$ and $E_{\text {int }}^{\mathrm{CP}}$ obtained by six MP2-type methods and CCSD(T) in combination with the aug-cc-pVTZ basis set

\begin{tabular}{|c|c|c|c|c|}
\hline \multirow[t]{2}{*}{ Method } & \multicolumn{2}{|c|}{$\mathrm{SnH}_{2}$-benzene } & \multicolumn{2}{|c|}{$\mathrm{SnH}_{2}$-pyridine } \\
\hline & $E_{\text {int }}$ & $E_{\text {int }}^{\mathrm{CP}}$ & $E_{\text {int }}$ & $E_{\text {int }}^{\mathrm{CP}}$ \\
\hline MP2 & $\begin{array}{l}-16.02 \\
(-3.23)\end{array}$ & $\begin{array}{l}-11.51 \\
(-2.42)\end{array}$ & $\begin{array}{l}-30.18 \\
(-2.45)\end{array}$ & $\begin{array}{l}-25.42 \\
(-2.05)\end{array}$ \\
\hline SCS-MP2 & $\begin{array}{l}-12.74 \\
(0.05)\end{array}$ & $\begin{array}{l}-8.83 \\
(0.25)\end{array}$ & $\begin{array}{l}-27.18 \\
(0.55)\end{array}$ & $\begin{array}{l}-22.83 \\
(0.53)\end{array}$ \\
\hline SOS-MP2 & $\begin{array}{l}-11.22 \\
(1.57)\end{array}$ & $\begin{array}{l}-7.60 \\
(1.48)\end{array}$ & $\begin{array}{l}-25.71 \\
(2.02)\end{array}$ & $\begin{array}{l}-21.57 \\
(1.80)\end{array}$ \\
\hline FE2-MP2 & $\begin{array}{l}-15.84 \\
(-3.05)\end{array}$ & $\begin{array}{l}-11.20 \\
(-2.12)\end{array}$ & $\begin{array}{l}-29.99 \\
(-2.26)\end{array}$ & $\begin{array}{l}-25.09 \\
(-1.72)\end{array}$ \\
\hline SCS(MI)-MP2 & $\begin{array}{l}-12.99 \\
(-0.20)\end{array}$ & $\begin{array}{l}-10.13 \\
(-1.05)\end{array}$ & $\begin{array}{l}-27.61 \\
(0.11)\end{array}$ & $\begin{array}{l}-24.42 \\
(-1.06)\end{array}$ \\
\hline S2-MP2 & $\begin{array}{l}-15.41 \\
(-2.62)\end{array}$ & $\begin{array}{l}-10.84 \\
(-1.76)\end{array}$ & $\begin{array}{l}-29.60 \\
(-1.88)\end{array}$ & $\begin{array}{l}-24.75 \\
(-1.38)\end{array}$ \\
\hline $\operatorname{CCSD}(\mathrm{T})$ & -12.79 & -9.08 & -27.73 & -23.36 \\
\hline
\end{tabular}

For the MP2-type methods the deviations of their two interaction energies from the values calculated using $\operatorname{CCSD}(\mathrm{T}) /$ aug-cc-pVTZ are shown in parentheses

All values in $\mathrm{kcal} \mathrm{mol}^{-1}$ $\pi$-complex the diffuse functions ascribed to $\mathrm{SnH}_{2}$ may overlap the centers of the benzene molecule), which causes an increase in the counterpoise correction for the BSSE [71]. The increase of BSSE by adding diffuse functions was also reported for the MP2/cc-pVDZ and MP2/aug-cc-pVDZ calculations of interaction energy in benzene dimers [72]. Third, the smallest deviations in $E_{\mathrm{int}}^{\mathrm{CP}}$ are found for SCS-MP2 irrespective of the basis set employed. The SCS(MI)-MP2 method produces the lowest values of the deviations in $E_{\text {int }}$ but only when combined with the aug-cc-pVTZ basis set. For the remaining three basis sets the SCS-MP2 method affords the best agreement with the $\operatorname{CCSD}(\mathrm{T})$ values of $E_{\text {int }}$. The conventional MP2 method, by contrast, always yields the most significant deviations in both $E_{\text {int }}$ and $E_{\text {int }}^{\mathrm{CP}}$, and this method severely overestimates the strength of the interaction between $\mathrm{SnH}_{2}$ and benzene/pyridine. Too negative values of $E_{\text {int }}$ and $E_{\text {int }}^{\mathrm{CP}}$ calculated by MP2 result from the application of the uncoupled HartreeFock dispersion energy that is known to be overestimated in MP2. The overestimation of the interaction in $\mathrm{SnH}_{2}$-benzene and $\mathrm{SnH}_{2}$-pyridine by the MP2 method is also accompanied by the shortening of the distance between $\mathrm{SnH}_{2}$ and benzene/ pyridine, as it was illustrated by the $d$ parameter and its deviation in Table 2. The poor performance of the conventional MP2 method was previously reported for predicting interaction energy in the complexes of transition metals with various ligands [67, 68], including benzene [73]. Two of these studies $[67,68]$ also showed that the SCS-MP2 method exhibits better performance in calculating the interaction energy than the conventional MP2 method, which is in line with our observation that SCS-MP2 is able to correct the MP2 overestimation of the interaction energy in $\mathrm{SnH}_{2}$-benzene and $\mathrm{SnH}_{2}$-pyridine.

Aside from the determination of $E_{\text {int }}$ and $E_{\text {int }}^{\mathrm{CP}}$ for $\mathrm{SnH}_{2}-$ benzene and $\mathrm{SnH}_{2}$-pyridine in their geometries optimized by different methods, it is essential to evaluate the performance of the MP2-type methods for the fixed geometries of the complexes. However, instead of inspecting a single geometry of each complex, we decided to do a survey of a set of geometries with a wide range of the values of the $d$ parameter. In each complex the geometries of the $\mathrm{SnH}_{2}$ and the benzene/pyridine moieties were fixed and a number of single-point calculations using the MP2-type methods and $\operatorname{CCSD}(\mathrm{T})$ were carried out for the $d$ parameter in the range from 2.0 to $5.0 \AA$. It should be stressed that for each value of the $d$ parameter the same geometry of a given complex was used by all the methods. The resulting set of points, whose coordinates are interaction energies and the corresponding $d$ values, can be presented graphically in the form of an interaction energy curve. For the purposes of illustration, the curves of $E_{\mathrm{int}}^{\mathrm{CP}}$ for the MP2-type and $\operatorname{CCSD}(\mathrm{T})$ methods combined with the aug-cc-pVTZ basis set are plotted in Fig. 3. The inspection of this figure clearly shows that the SCS-MP2 method provides best agreements with the $\operatorname{CCSD}(\mathrm{T})$ results. The SCS-MP2 curve for the $\pi$ complex almost perfectly matches the reference curve of $E_{\text {int }}^{\mathrm{CP}}$, 
Fig. $3 E_{\text {int }}^{\mathrm{CP}}$ for the $\pi$-complex of $\mathrm{SnH}_{2}$ with benzene (top) and the $\sigma$-complex of $\mathrm{SnH}_{2}$ with pyridine (bottom) as a function of the geometrical parameter $d$. The MP2-type and CCSD(T) methods were combined with the aug-cc-pVTZ basis set
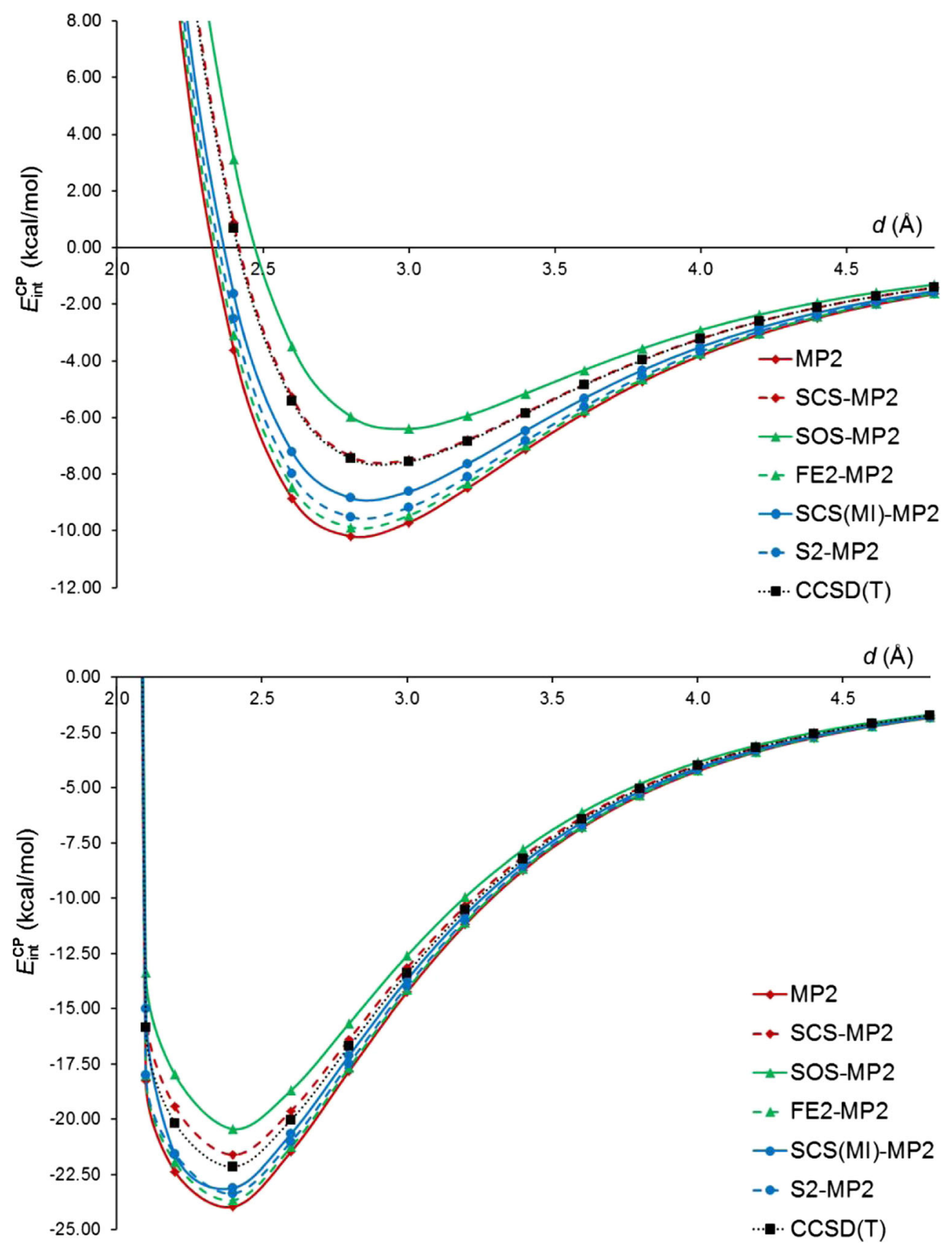

whereas the SCS-MP2 curve for the $\sigma$-complex is slightly above the $\operatorname{CCSD}(\mathrm{T})$ curve. The SOS-MP2 curve for the $\sigma$ complex is even higher than the SCS-MP2 one and the same can be noticed for the $\pi$-complex. By contrast, the curves computed with FE2-MP2, SCS(MI)-MP2, S2-MP2, and MP2 are below the $\operatorname{CCSD}(\mathrm{T})$ curve in the minimum region as well as for larger $d$ in both complexes. The behavior of the MP2-type methods for larger $d$ values may be important for investigating the interaction between aromatic molecules and stannylenes containing a bulky substituent. For instance, it is known that some N-heterocyclic stannylenes exhibit Sn-aryl contacts of $3.51 \AA$ [74]. Our observations for the interaction energy curves of $\mathrm{SnH}_{2}$-benzene are similar to those made by Takatani and Sherrill [75] for interaction energy curves in the methane-benzene and $\mathrm{H}_{2} \mathrm{~S}$-benzene complexes. Authors noticed that SCS-MP2 offered striking improvements over the conventional MP2 method for the reproduction of the $\operatorname{CCSD}(\mathrm{T})$ interaction energy curves of these two complexes. For the $\mathrm{H}_{2} \mathrm{~S}$-benzene complex the SCS-MP2 method underestimated, however, interaction energies compared to $\operatorname{CCSD}(\mathrm{T})$.

In order to assess quantitatively the performance of the MP2-type methods in reproducing the $\operatorname{CCSD}(\mathrm{T})$ curves of $E_{\text {int }}$ and $E_{\text {int }}^{\mathrm{CP}}$ for $\mathrm{SnH}_{2}$-benzene and $\mathrm{SnH}_{2}$-pyridine, a set of 13 
points in the minimum region and also for larger $d$ values was selected. For the set of points obtained with each MP2-type method, the mean signed error (MSE) and the root mean square error (RMSE) with respect to the reference CCSD(T) data were calculated (more details of the MSE and RMSE calculations can be found in section S1, see Electronic supplementary material). Table 4 presents the values of MSE and RMSE in $E_{\text {int }}$ and $E_{\text {int }}^{\mathrm{CP}}$ computed with six MP2-type methods in combination with the aug-cc-pVTZ basis set (results for the remaining three basis sets are gathered in Tables S7-S9, see Electronic supplementary material). The conclusions drawn from the visual inspection of Fig. 3 are confirmed quantitatively by the results in Table 4 . The errors for SCS-MP2 are up to two orders of magnitude lower than the errors for the other MP2-type methods. Moreover, the performance of SCS-MP2 is similar in reproducing the curves of both $E_{\text {int }}$ and $E_{\text {int }}^{\mathrm{CP}}$. These findings are valid for all four basis sets.

\section{Assessment of DFT methods}

Now we turn our attention to the assessment of the performances of 14 DFT methods and this assessment will be carried out using the same evaluation procedures as those applied to the MP2-type methods. The first evaluation procedure involves calculating RMSD for the DFT-optimized structures with respect to the geometries of the $\mathrm{SnH}_{2}$-benzene and $\mathrm{SnH}_{2}$-pyridine complexes optimized using the reference CCSD method. The resulting values of RMSD are presented graphically in Fig. 4. In order to obtain each RMSD value, a pair of structures optimized using the same basis set was considered. However, as mentioned in the Computational details section, the structures optimized by DFT in conjunction with def2-TZVP and def2-TZVPD were referenced to the structures computed by CCSD/def2-TZVPP and CCSD/def2TZVPPD, respectively. A quick glance at Fig. 4 reveals that the values of RMSD for the $\sigma$-complex are generally much smaller than the RMSD values for the $\pi$-complex. The same was observed for the MP2-type methods in Fig. 2. Hence, providing a reliable structural description for the $\pi$ complexation between $\mathrm{SnH}_{2}$ and benzene is a real challenge both for the MP2-type methods and for the DFT methods.

A detailed analysis of Fig. 4 indicates that two modern standard density functionals, namely $\omega \mathrm{B} 97 \mathrm{X}$ and M11, yield the $\pi$-complex geometries that are in good agreement with the reference structure. These density functionals also perform well in reproducing the CCSD geometry of the $\sigma$-complex but additionally the list of the density functionals that are the most suitable for this complex can be extended by the TPSSh density functional. The B3LYP hybrid density functional exhibits disappointing performance in reproducing the structures of both complexes. It is rather not surprising because the poor performance of this functional was detected for the structures of transition-metal complexes from the first [76, 77] and subsequent rows $[7,8]$. The comparative study performed by Bühl and Kabrede [76] also showed that B3LYP was outperformed by BP86, TPSS, and TPSSh when equilibrium geometries for a diverse set of 32 metal complexes were taken into consideration. Our results agree with the aforementioned findings. Our observation on the good performance of RSH density functionals seems to extend the findings of two previous benchmark studies $[7,78]$ in which the $\omega$ B97X-D density functional emerged as the most suitable functional for predicting geometries of transition-metal complexes.

It is crucial to discuss the effect of the dispersion correction incorporated into the DFT methods on the reproduction of the geometries of $\mathrm{SnH}_{2}$-benzene and $\mathrm{SnH}_{2}$-pyridine. The comparison of the RMSD values obtained from standard density functionals with the RMSD values yielded by the corresponding dispersion-corrected density functionals indicates that it is difficult to find any systematic change in all these RMSD values. Moreover, even for a single complex the effect of the dispersion correction turns out to be erratic. For the

Table 4 MSE and RMSE for $E_{\text {int }}$ and $E_{\text {int }}^{\mathrm{CP}}$ across the interaction energy curves for the $\mathrm{SnH}_{2}$-benzene and $\mathrm{SnH}_{2}$-pyridine complexes

\begin{tabular}{|c|c|c|c|c|c|c|c|c|}
\hline \multirow[t]{3}{*}{ Method } & \multicolumn{4}{|c|}{$\mathrm{SnH}_{2}$-benzene } & \multicolumn{4}{|c|}{$\mathrm{SnH}_{2}$-pyridine } \\
\hline & \multicolumn{2}{|l|}{$E_{\mathrm{int}}$} & \multicolumn{2}{|l|}{$E_{\mathrm{int}}^{\mathrm{CP}}$} & \multicolumn{2}{|l|}{$E_{\mathrm{int}}$} & \multicolumn{2}{|l|}{$E_{\mathrm{int}}^{\mathrm{CP}}$} \\
\hline & MSE & RMSE & MSE & RMSE & MSE & RMSE & MSE & RMSE \\
\hline MP2 & -1.64 & 2.14 & -1.48 & 1.95 & -0.89 & 1.16 & -0.77 & 1.01 \\
\hline SCS-MP2 & 0.04 & 0.07 & 0.05 & 0.08 & 0.21 & 0.31 & 0.21 & 0.31 \\
\hline SOS-MP2 & 0.88 & 1.16 & 0.81 & 1.08 & 0.77 & 1.04 & 0.70 & 0.96 \\
\hline FE2-MP2 & -1.55 & 2.01 & -1.31 & 1.72 & -0.83 & 1.07 & -0.65 & 0.84 \\
\hline SCS(MI)-MP2 & -0.13 & 0.26 & -0.75 & 1.01 & 0.14 & 0.16 & -0.36 & 0.54 \\
\hline S2-MP2 & -1.33 & 1.73 & -1.11 & 1.46 & -0.69 & 0.89 & -0.52 & 0.67 \\
\hline
\end{tabular}

The errors are calculated for the energies obtained from MP2 and its variants combined with the aug-cc-pVTZ basis set with respect to the CCSD(T)/augcc-pVTZ energies

All values in $\mathrm{kcal} \mathrm{mol}^{-1}$ 

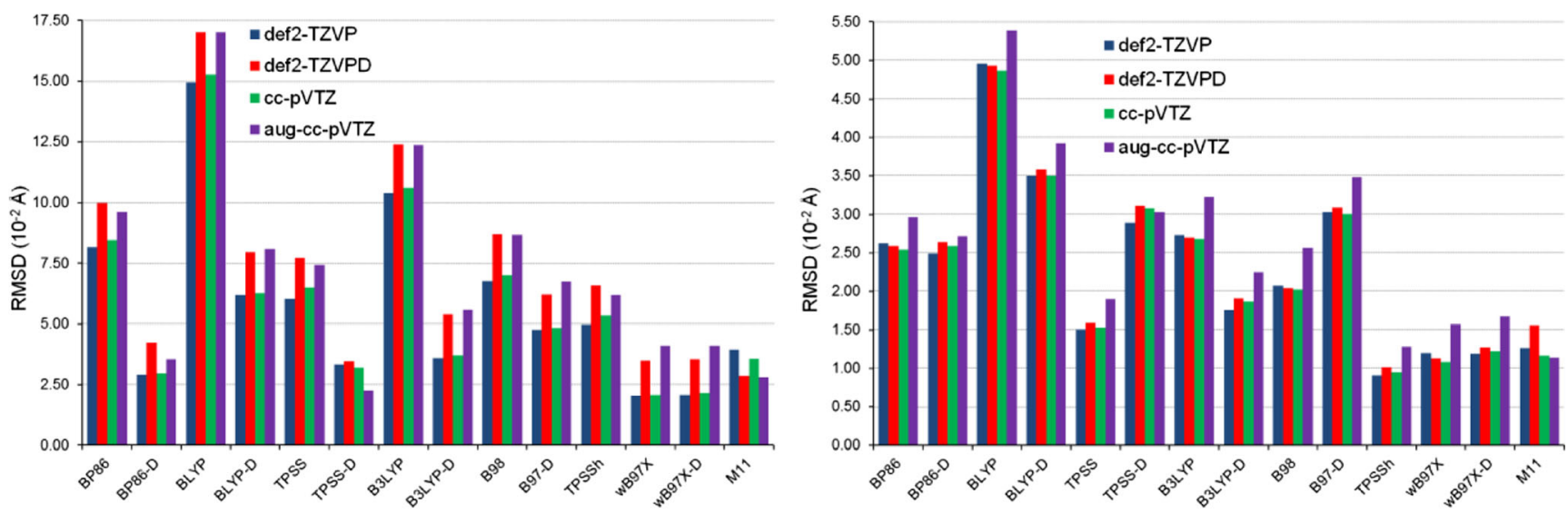

Fig. 4 RMSD for the $\pi$-complex of $\mathrm{SnH}_{2}$ with benzene (left) and the $\sigma$-complex of $\mathrm{SnH}_{2}$ with pyridine (right) obtained by 14 DFT methods in combination with four basis sets

$\sigma$-complex the inclusion of the dispersion correction in BLYP and B3LYP leads to an improvement in the performance of these two density functionals. The reverse situation can be seen for TPSS and B98. The reproduction of the $\sigma$-complex geometry by BP86-D and $\omega$ B97X-D is hardly affected by the presence of the dispersion correction. In the case of the $\pi$ complex, the density functionals belonging to non-RSH generations benefit greatly from the addition of the dispersion correction. In consequence, such dispersion-corrected density functionals as BP86-D and TPSS-D are capable of providing the RMSD values that are very close to those obtained by the RSH density functionals. The accuracy of the $\pi$-complex geometry optimized by $\omega \mathrm{B} 97 \mathrm{X}$ is practically insensitive to the dispersion correction. The absence of any systematic change in the RMSD values obtained by the dispersion-corrected density functionals for both complexes may be due to the fact that the dispersion correction used in this work is a simple empirical correction that covers no system dependence for its damping function and coefficients [58]. Such an absence may, to some extent, illustrate differences between the $\pi$ complexation and the $\sigma$-complexation (inspecting the nature of such possible differences in detail is, however, beyond the scope of this work). The findings presented in this paragraph are in qualitative agreement with the results of the very recent DFT benchmark by Weymuth et al. [79]. These authors observed a relatively significant influence of dispersion corrections on structures of transition-metal complexes and, what is more important, the structures optimized using different dispersion-corrected density functionals deviated strongly from each other.

The ranking of the density functionals ordered with respect to their RMSD values is rather insensitive to the basis set applied. However, the RMSD value computed with a given density functional and with a given basis set may differ quite noticeably from the RMSD value calculated using the same density functional but combined with a different basis set. In general, augmenting def2-TZVP or cc-pVTZ with their diffuse functions leads to an increase in the values of RMSD for the majority of the density functionals considered. M11 presents an exceptional behavior for Dunning's basis set and its lowest RMSD values can be found for its combination with the aug-cc-pVTZ basis set.

Since the evaluation procedure utilizing RMSD was applied to the assessment of both the MP2-type and the DFT methods, it is interesting to inspect whether the former can be an alternative to the latter for reproducing the structures of the $\mathrm{SnH}_{2}$-benzene and $\mathrm{SnH}_{2}$-pyridine complexes. If the RMSD values shown in Fig. 2 are juxtaposed with those in Fig. 4, it is evident that the best MP2-type methods (namely, SOS-MP2 and SCS-MP2) outperform the best DFT methods (e.g., $\omega \mathrm{B} 97 \mathrm{X})$. More specifically, the latter produce the RMSD values approximately twice as large as the RMSD values calculated with the former methods. It implies that, of all methods considered, SOS-MP2 and SCS-MP2 are the most suitable for reproducing the reference CCSD geometries of $\mathrm{SnH}_{2}$-benzene and $\mathrm{SnH}_{2}$-pyridine. Another important issue that deserves noting here is the assessment of the conventional MP2 method by comparing with the performance of the RSH density functionals. Such a comparison reveals that the performance of MP2 in reproducing the geometry of the $\pi$ complex is far from acceptable. On the other hand, the conventional MP2 method provides the structural description of the $\sigma$-complexation that is comparable to that yielded by the RSH density functionals. The inferior performance of MP2 in comparison to $\omega \mathrm{B} 97 \mathrm{X}$ and $\omega \mathrm{B} 97 \mathrm{X}-\mathrm{D}$ was reported by Kulkarni and Truhlar in their comparative study of structural parameters in $\mathrm{Ru}$ complexes [7].

The values of three characteristic structural parameters describing the interaction between $\mathrm{SnH}_{2}$ and benzene/pyridine in the $\mathrm{SnH}_{2}$-benzene and $\mathrm{SnH}_{2}$-pyridine complexes are listed in Table 5. The tabulated values were obtained from the DFT calculations using the aug-cc-pVTZ basis set (results for the remaining three basis sets can be found in Tables S10-S12, see Electronic supplementary material). The deviations in $d, a_{1}$, 
Table 5 Selected geometrical parameters $\left(d, a_{1}\right.$, and $\left.a_{2}\right)$ for the $\pi$ complex of $\mathrm{SnH}_{2}$ with benzene and for the $\sigma$-complex of $\mathrm{SnH}_{2}$ with pyridine optimized by 14 DFT methods in combination with the augcc-pVTZ basis set

\begin{tabular}{|c|c|c|c|c|c|c|}
\hline \multirow[t]{2}{*}{ Method } & \multicolumn{3}{|c|}{$\mathrm{SnH}_{2}$-benzene } & \multicolumn{3}{|c|}{$\mathrm{SnH}_{2}$-pyridine } \\
\hline & $d$ & $a_{1}$ & $a_{2}$ & $d$ & $a_{1}$ & $a_{2}$ \\
\hline BP86 & $\begin{array}{l}2.838 \\
(0.012)\end{array}$ & $\begin{array}{l}85.07 \\
(-4.50)\end{array}$ & $\begin{array}{l}19.00 \\
(4.72)\end{array}$ & $\begin{array}{l}2.391 \\
(0.056)\end{array}$ & $\begin{array}{l}119.91 \\
(-0.22)\end{array}$ & $\begin{array}{l}5.63 \\
(0.02)\end{array}$ \\
\hline BP86-D & $\begin{array}{l}2.834 \\
(0.007)\end{array}$ & $\begin{array}{l}88.16 \\
(-1.40)\end{array}$ & $\begin{array}{l}16.67 \\
(2.39)\end{array}$ & $\begin{array}{l}2.381 \\
(0.046)\end{array}$ & $\begin{array}{l}120.85 \\
(0.73)\end{array}$ & $\begin{array}{l}8.26 \\
(2.65)\end{array}$ \\
\hline BLYP & $\begin{array}{l}2.987 \\
(0.161)\end{array}$ & $\begin{array}{l}81.23 \\
(-8.34)\end{array}$ & $\begin{array}{l}22.72 \\
(8.45)\end{array}$ & $\begin{array}{l}2.444 \\
(0.109)\end{array}$ & $\begin{array}{l}120.04 \\
(-0.08)\end{array}$ & $\begin{array}{l}5.36 \\
(-0.25)\end{array}$ \\
\hline BLYP-D & $\begin{array}{l}2.948 \\
(0.122)\end{array}$ & $\begin{array}{l}85.84 \\
(-3.73)\end{array}$ & $\begin{array}{l}18.62 \\
(4.35)\end{array}$ & $\begin{array}{l}2.426 \\
(0.091)\end{array}$ & $\begin{array}{l}120.92 \\
(0.80)\end{array}$ & $\begin{array}{l}7.99 \\
(2.39)\end{array}$ \\
\hline TPSS & $\begin{array}{l}2.810 \\
(-0.016)\end{array}$ & $\begin{array}{l}86.04 \\
(-3.53)\end{array}$ & $\begin{array}{l}19.20 \\
(4.92)\end{array}$ & $\begin{array}{l}2.376 \\
(0.041)\end{array}$ & $\begin{array}{l}120.38 \\
(0.26)\end{array}$ & $\begin{array}{l}6.70 \\
(1.09)\end{array}$ \\
\hline TPSS-D & $\begin{array}{l}2.805 \\
(-0.021)\end{array}$ & $\begin{array}{l}89.19 \\
(-0.37)\end{array}$ & $\begin{array}{l}16.58 \\
(2.31)\end{array}$ & $\begin{array}{l}2.369 \\
(0.034)\end{array}$ & $\begin{array}{l}121.39 \\
(1.26)\end{array}$ & $\begin{array}{l}9.40 \\
(3.79)\end{array}$ \\
\hline B3LYP & $\begin{array}{l}2.949 \\
(0.123)\end{array}$ & $\begin{array}{l}83.29 \\
(-6.28)\end{array}$ & $\begin{array}{l}20.87 \\
(6.59)\end{array}$ & $\begin{array}{l}2.409 \\
(0.074)\end{array}$ & $\begin{array}{l}119.96 \\
(-0.17)\end{array}$ & $\begin{array}{l}5.32 \\
(-0.29)\end{array}$ \\
\hline B3LYP-D & $\begin{array}{l}2.926 \\
(0.100)\end{array}$ & $\begin{array}{l}86.75 \\
(-2.82)\end{array}$ & $\begin{array}{l}17.82 \\
(3.54)\end{array}$ & $\begin{array}{l}2.399 \\
(0.064)\end{array}$ & $\begin{array}{l}120.77 \\
(0.64)\end{array}$ & $\begin{array}{l}7.61 \\
(2.01)\end{array}$ \\
\hline B98 & $\begin{array}{l}2.902 \\
(0.076)\end{array}$ & $\begin{array}{l}85.39 \\
(-4.18)\end{array}$ & $\begin{array}{l}18.83 \\
(4.56)\end{array}$ & $\begin{array}{l}2.395 \\
(0.060)\end{array}$ & $\begin{array}{l}119.98 \\
(-0.14)\end{array}$ & $\begin{array}{l}5.50 \\
(-0.11)\end{array}$ \\
\hline B97-D & $\begin{array}{l}2.960 \\
(0.134)\end{array}$ & $\begin{array}{l}87.24 \\
(-2.33)\end{array}$ & $\begin{array}{l}16.47 \\
(2.19)\end{array}$ & $\begin{array}{l}2.421 \\
(0.086)\end{array}$ & $\begin{array}{l}120.59 \\
(0.47)\end{array}$ & $\begin{array}{l}7.18 \\
(1.57)\end{array}$ \\
\hline TPSSh & $\begin{array}{l}2.808 \\
(-0.018)\end{array}$ & $\begin{array}{l}86.61 \\
(-2.96)\end{array}$ & $\begin{array}{l}18.44 \\
(4.17)\end{array}$ & $\begin{array}{l}2.368 \\
(0.033)\end{array}$ & $\begin{array}{l}120.29 \\
(0.17)\end{array}$ & $\begin{array}{l}6.46 \\
(0.85)\end{array}$ \\
\hline$\omega B 97 X$ & $\begin{array}{l}2.919 \\
(0.093)\end{array}$ & $\begin{array}{l}88.19 \\
(-1.38)\end{array}$ & $\begin{array}{l}16.11 \\
(1.84)\end{array}$ & $\begin{array}{l}2.380 \\
(0.045)\end{array}$ & $\begin{array}{l}120.24 \\
(0.12)\end{array}$ & $\begin{array}{l}5.81 \\
(0.21)\end{array}$ \\
\hline$\omega B 97 X-D$ & $\begin{array}{l}2.923 \\
(0.097)\end{array}$ & $\begin{array}{l}88.33 \\
(-1.24)\end{array}$ & $\begin{array}{l}16.54 \\
(2.27)\end{array}$ & $\begin{array}{l}2.384 \\
(0.049)\end{array}$ & $\begin{array}{l}120.49 \\
(0.37)\end{array}$ & $\begin{array}{l}6.44 \\
(0.83)\end{array}$ \\
\hline M11 & $\begin{array}{l}2.855 \\
(0.029)\end{array}$ & $\begin{array}{l}90.68 \\
(1.11)\end{array}$ & $\begin{array}{l}13.03 \\
(-1.24)\end{array}$ & $\begin{array}{l}2.364 \\
(0.029)\end{array}$ & $\begin{array}{l}120.56 \\
(0.44)\end{array}$ & $\begin{array}{l}6.72 \\
(1.11)\end{array}$ \\
\hline CCSD & 2.826 & 89.57 & 14.27 & 2.335 & 120.12 & 5.61 \\
\hline
\end{tabular}

The deviations of the three parameters from the values calculated using CCSD/aug-cc-pVTZ are shown in parentheses. In the last row there are the CCSD/aug-cc-pVTZ results, repeated after Table 2

Distances in $\AA$, angles in ${ }^{\circ}$

and $a_{2}$ calculated by 14 density functionals from the corresponding CCSD/aug-cc-pVTZ results are also presented in Table 5. The analysis of these deviations and the findings made in terms of RMSD in the previous paragraphs are broadly similar and they lead to identical conclusions on the performance of individual density functionals. Besides, the results shown in Table 5 allow us to gain a more detailed structural picture of complexation in $\mathrm{SnH}_{2}$-benzene and $\mathrm{SnH}_{2}$-pyridine. On the basis of many positive deviations in $d$, it is apparent that the majority of the DFT methods overestimate the $d$ distance in both complexes. All DFT methods except M11 predict that the $\mathrm{SnH}_{2}$ molecule is moved slightly outward the carbon ring of the benzene molecule (as is indicated by $a_{1}<$ $90^{\circ}$ ) and the molecular plane of $\mathrm{SnH}_{2}$ is inclined toward the benzene plane to a greater extent than it is observed in the $\pi$ complex optimized by CCSD. The deviations in $a_{1}$ and $a_{2}$ for the $\sigma$-complex do not show clear regularities but they are generally much smaller than those obtained for the $\pi$ complex.

Next, for the $\mathrm{SnH}_{2}$-benzene and $\mathrm{SnH}_{2}$-pyridine complexes optimized by 14 DFT methods, the uncorrected and counterpoise-corrected interaction energies between $\mathrm{SnH}_{2}$ and benzene/pyridine were calculated using these methods. The values of $E_{\text {int }}$ and $E_{\text {int }}^{\mathrm{CP}}$ obtained from the DFT methods in conjunction with the aug-cc-pVTZ basis set are listed in Table 6 (results for the remaining three basis sets are gathered in Tables S13-S15, see Electronic supplementary material). In order to evaluate the performance of the DFT methods in predicting $E_{\text {int }}$ and $E_{\text {int }}^{\mathrm{CP}}$, Table 6 also presents the deviations

Table $6 E_{\text {int }}$ and $E_{\text {int }}^{\mathrm{CP}}$ for the $\pi$-complex of $\mathrm{SnH}_{2}$ with benzene and for the $\sigma$-complex of $\mathrm{SnH}_{2}$ with pyridine optimized by 14 DFT methods in combination with the aug-cc-pVTZ basis set

\begin{tabular}{|c|c|c|c|c|}
\hline \multirow[t]{2}{*}{ Method } & \multicolumn{2}{|c|}{$\mathrm{SnH}_{2}$-benzene } & \multicolumn{2}{|c|}{$\mathrm{SnH}_{2}$-pyridine } \\
\hline & $E_{\text {int }}$ & $E_{\text {int }}^{\mathrm{CP}}$ & $E_{\text {int }}$ & $E_{\text {int }}^{\mathrm{CP}}$ \\
\hline BP86 & $\begin{array}{l}-6.63 \\
(6.16)\end{array}$ & $\begin{array}{l}-6.62 \\
(2.46)\end{array}$ & $\begin{array}{l}-21.35 \\
(6.38)\end{array}$ & $\begin{array}{l}-21.15 \\
(2.22)\end{array}$ \\
\hline BP86-D & $\begin{array}{l}-12.50 \\
(0.29)\end{array}$ & $\begin{array}{l}-12.32 \\
(-3.23)\end{array}$ & $\begin{array}{l}-25.73 \\
(2.00)\end{array}$ & $\begin{array}{l}-25.52 \\
(-2.16)\end{array}$ \\
\hline BLYP & $\begin{array}{l}-4.11 \\
(8.68)\end{array}$ & $\begin{array}{l}-4.10 \\
(4.98)\end{array}$ & $\begin{array}{l}-18.40 \\
(9.33)\end{array}$ & $\begin{array}{l}-18.20 \\
(5.16)\end{array}$ \\
\hline BLYP-D & $\begin{array}{l}-10.43 \\
(2.36)\end{array}$ & $\begin{array}{l}-10.27 \\
(-1.19)\end{array}$ & $\begin{array}{l}-23.28 \\
(4.45)\end{array}$ & $\begin{array}{l}-23.07 \\
(0.29)\end{array}$ \\
\hline TPSS & $\begin{array}{l}-7.36 \\
(5.42)\end{array}$ & $\begin{array}{l}-7.23 \\
(1.85)\end{array}$ & $\begin{array}{l}-22.40 \\
(5.33)\end{array}$ & $\begin{array}{l}-22.23 \\
(1.14)\end{array}$ \\
\hline TPSS-D & $\begin{array}{l}-12.93 \\
(-0.14)\end{array}$ & $\begin{array}{l}-12.79 \\
(-3.71)\end{array}$ & $\begin{array}{l}-26.63 \\
(1.10)\end{array}$ & $\begin{array}{l}-26.46 \\
(-3.09)\end{array}$ \\
\hline B3LYP & $\begin{array}{l}-4.92 \\
(7.87)\end{array}$ & $\begin{array}{l}-4.92 \\
(4.17)\end{array}$ & $\begin{array}{l}-19.60 \\
(8.13)\end{array}$ & $\begin{array}{l}-19.43 \\
(3.93)\end{array}$ \\
\hline B3LYP-D & $\begin{array}{l}-10.63 \\
(2.16)\end{array}$ & $\begin{array}{l}-10.49 \\
(-1.40)\end{array}$ & $\begin{array}{l}-23.94 \\
(3.79)\end{array}$ & $\begin{array}{l}-23.77 \\
(-0.40)\end{array}$ \\
\hline B98 & $\begin{array}{l}-6.71 \\
(6.08)\end{array}$ & $\begin{array}{l}-6.73 \\
(2.36)\end{array}$ & $\begin{array}{l}-20.98 \\
(6.75)\end{array}$ & $\begin{array}{l}-20.82 \\
(2.54)\end{array}$ \\
\hline B97-D & $\begin{array}{l}-10.93 \\
(1.86)\end{array}$ & $\begin{array}{l}-10.87 \\
(-1.79)\end{array}$ & $\begin{array}{l}-23.07 \\
(4.66)\end{array}$ & $\begin{array}{l}-22.88 \\
(0.48)\end{array}$ \\
\hline TPSSh & $\begin{array}{l}-7.38 \\
(5.41)\end{array}$ & $\begin{array}{l}-7.26 \\
(1.83)\end{array}$ & $\begin{array}{l}-22.43 \\
(5.30)\end{array}$ & $\begin{array}{l}-22.28 \\
(1.09)\end{array}$ \\
\hline$\omega B 97 X$ & $\begin{array}{l}-9.38 \\
(3.41)\end{array}$ & $\begin{array}{c}-9.28 \\
(-0.19)\end{array}$ & $\begin{array}{l}-24.07 \\
(3.66)\end{array}$ & $\begin{array}{l}-23.83 \\
(-0.46)\end{array}$ \\
\hline$\omega B 97 X-D$ & $\begin{array}{l}-9.92 \\
(2.87)\end{array}$ & $\begin{array}{r}-9.86 \\
(-0.77)\end{array}$ & $\begin{array}{l}-23.75 \\
(3.98)\end{array}$ & $\begin{array}{l}-23.56 \\
(-0.19)\end{array}$ \\
\hline M11 & $\begin{array}{l}-10.31 \\
(2.48)\end{array}$ & $\begin{array}{c}-9.77 \\
(-0.68)\end{array}$ & $\begin{array}{l}-23.79 \\
(3.94)\end{array}$ & $\begin{array}{l}-23.40 \\
(-0.04)\end{array}$ \\
\hline $\operatorname{CCSD}(\mathrm{T})$ & -12.79 & -9.08 & -27.73 & -23.36 \\
\hline
\end{tabular}

The deviations of the two interaction energies from the values calculated using CCSD(T)/aug-cc-pVTZ are shown in parentheses. In the last row there are the $\operatorname{CCSD}(\mathrm{T}) /$ aug-cc-pVTZ results, repeated after Table 3

All values in $\mathrm{kcal} \mathrm{mol}^{-1}$ 
of the DFT results from the CCSD(T)/aug-cc-pVTZ interaction energies calculated for the complex geometries optimized at the CCSD/aug-cc-pVTZ level of theory. As it can be seen in this table, the TPSS-D density functional yields the smallest deviations in $E_{\text {int }}$, whereas $\omega \mathrm{B} 97 \mathrm{X}$ and M11 give the best agreements for $E_{\text {int }}^{\mathrm{CP}}$ in $\mathrm{SnH}_{2}$-benzene and $\mathrm{SnH}_{2}$-pyridine, respectively. This suggests that there is no single density functional that is the most accurate for $E_{\text {int }}$ and $E_{\text {int }}^{\mathrm{CP}}$ in both complexes. As a matter of fact, the ranking of the DFT methods ordered with respect to their performance for $E_{\text {int }}$ is not exactly the same as the ranking compiled for $E_{\text {int }}^{\mathrm{CP}}$. Moreover, the performance of the DFT methods turns out to be rather sensitive to the choice of basis set. Nevertheless, some regularities in the calculated interaction energies and in their deviations from the $\operatorname{CCSD}(\mathrm{T})$ results can be found. The BLYP density functional produces the largest deviations in $E_{\text {int }}$, irrespective of the basis set applied. The performance of this functional in reproducing $E_{\mathrm{int}}^{\mathrm{CP}}$ is also very poor but it is not necessarily associated with the largest deviations for all basis sets. The poor performance of BLYP seems to be due to the LYP correlation [80] incorporated in this density functional. It was previously reported that density functionals with the LYP correlation failed in describing some coinage metal systems [81-83]. The LYP correlation does not satisfy the correct uniform electron gas limit, which was the reason for the poor performance of the BLYP density functional in modeling coinage metal systems and most probably in our case as well. B3LYP outperforms BLYP but the performance of the former in reproducing $E_{\mathrm{int}}$ and $E_{\mathrm{int}}^{\mathrm{CP}}$ is also unsatisfactory, which again can be explained by the presence of the LYP correlation. In addition, it is known that the B3LYP density functional tends to overestimate the absolute exchange and correlation energies of molecules containing metals compared to accurate coupled cluster calculations [84]. If BLYP and B3LYP are not under consideration, the remaining GGA and GH GGA density functionals (that is, BP86 and B98) exhibit larger deviations in $E_{\text {int }}$ and $E_{\text {int }}^{\mathrm{CP}}$ for both complexes than the meta-GGA and GH meta-GGA density functionals (that is, TPSS and TPSSh). The deviations yielded by TPSS are much the same as those obtained by TPSSh for all four basis sets. The accuracies exhibited by BP86 and TPSS are in accord with the 'Jacob's ladder' classification of DFT methods [85]. Moving up from the second rung (GGA) to the third rung (meta-GGA), indeed, leads to the improvement in the predicted values of $E_{\text {int }}$ and $E_{\text {int }}^{\mathrm{CP}}$. The performance of the RSH density functionals in reproducing $E_{\text {int }}$ is good in the sense that their deviations are lower than those of meta-GGA and GH meta-GGA for both complexes and for all basis sets. In the case of $E_{\text {int }}^{\mathrm{CP}}$, the performance of $\omega \mathrm{B} 97 \mathrm{X}$ and M11 is, however, dependent on the basis set employed. Only the most extended basis set, namely aug-cc-pVTZ, allows these two density functionals to predict $E_{\text {int }}^{\mathrm{CP}}$ with great accuracy. Our conclusions are in line with the results of a previous benchmark study devoted to the performance of density functional for the bond energetics of $3 d$ transition-metal compounds [77]. For such compounds B3LYP is outperformed by BP86 and the following functionals are TPSS and TPSSh. The good performance of M11 is not well-established in the literature and even the latest comparative studies of Minnesota density functionals often do not include this functional [86-88]. It has been reported so far that M11 emerges as a very reliable functional for the study of the energetics of sulfate-water clusters [89]. From a more general perspective, it was recently suggested that the introduction of range-separation can fix errors caused by the absence of dispersion corrections in standard density functionals and an improvement in interaction energies calculated by range-separated density functionals was observed for Grubbs catalysts [90]. The improvement can most probably be ascribed to some cancellation of errors as range-separation selectively turns off the gradient-corrected part of density functionals and it leads to LDA-type overbinding [90]. The results presented in Table 6 confirm that the RSH density functionals predict stronger interaction between $\mathrm{SnH}_{2}$ and benzene/pyridine than the GGA density functionals.

As can be seen in Table 6, the effect of the dispersion correction on the values of $E_{\text {int }}$ and $E_{\text {int }}^{\mathrm{CP}}$ is rather erratic. On the one hand, the addition of the dispersion correction decreases the deviations in $E_{\text {int }}$ for all dispersion-corrected density functionals except for $\omega \mathrm{B} 97 \mathrm{X}-\mathrm{D}$ in $\mathrm{SnH}_{2}$-pyridine. Such an effect is valid for all four basis sets. On the other hand, the effect of the dispersion correction on the values of $E_{\text {int }}^{\mathrm{CP}}$ is heavily dependent on the density functional, basis set and kind of complex. The lack of a uniform improvement of density functionals by dispersion corrections was also detected for the interaction between gold and unsaturated aliphatic hydrocarbons [68]. We observe, however, that the addition of the D correction to BLYP and B3LYP consistently improves their $E_{\text {int }}^{\mathrm{CP}}$ values.

Another important issue is how the choice of basis set affects the values of $E_{\text {int }}$ and $E_{\text {int }}^{\mathrm{CP}}$. For each DFT method, its values of $E_{\text {int }}$ obtained using the cc-pVTZ basis set are fairly similar to those calculated with def2-TZVP. The same can be observed for $E_{\text {int }}^{\mathrm{CP}}$. The differences between interaction energies computed with these two basis sets do not exceed $0.65 \mathrm{kcal} \mathrm{mol}^{-1}$. The presence of diffuse functions in def2TZVPD and aug-cc-pVTZ often increases the deviations in $E_{\text {int }}$ and $E_{\text {int }}^{\mathrm{CP}}$ compared to the corresponding deviations yielded by the DFT methods in conjunction with def2-TZVP and cc-pVTZ. However, combining the dispersion-corrected or RSH density functionals with the diffuse-augmented basis sets leads to the $E_{\text {int }}^{\mathrm{CP}}$ values that are in better agreement with the reference results.

It is essential to estimate the accuracy of the DFT methods for reproducing $E_{\text {int }}$ and $E_{\text {int }}^{\mathrm{CP}}$ from a more global viewpoint, covering the variations in $E_{\text {int }}$ and $E_{\text {int }}^{\mathrm{CP}}$ obtained by both the DFT and the MP2-type methods with respect to the reference 
$\operatorname{CCSD}(\mathrm{T})$ data. A closer inspection of the variations in $E_{\mathrm{int}}$ calculated using the DFT and MP2-type methods reveals that the $E_{\text {int }}$ values yielded by the former methods differ more significantly from the reference values (compare the $E_{\text {int }}$ values and their variations in Tables 3 and 6). It is largely due to the fact that the $E_{\text {int }}$ values calculated using the MP2type methods are affected by the BSSE to the extent that is similar to that observed for the $\operatorname{CCSD}(\mathrm{T})$ values. By contrast, the DFT methods produce the $E_{\text {int }}$ values that are hardly influenced by the BSSE (compare $E_{\text {int }}$ and $E_{\text {int }}^{\mathrm{CP}}$ in Table 6). If one collates the variations in $E_{\mathrm{int}}^{\mathrm{CP}}$ produced by the DFT methods with the variations in $E_{\text {int }}^{\mathrm{CP}}$ predicted by SCS-MP2, it is clear that the SCS-MP2 method generally outperforms the DFT methods in reproducing the $\operatorname{CCSD}(\mathrm{T})$ values of $E_{\text {int }}^{\mathrm{CP}}$. The variations in $E_{\text {int }}^{\mathrm{CP}}$ yielded by the DFT methods are heavily dependent on the choice of basis set and, therefore, it is impossible to find a single density functional that combined with all considered basis sets always achieves accuracy that is comparable to that of SCS-MP2. This finding stands in marked contrast to the results obtained for dissociation energies of gold complexes whose dissociation energies were predicted by the best performing DFT methods more accurately than by SCS-MP2 [68].

As the next stage of the assessment of the DFT methods, the ability of these methods to reproduce the interaction energies as a function of the $d$ parameter in the $\mathrm{SnH}_{2}$-benzene and $\mathrm{SnH}_{2}$-pyridine complexes has been studied. It allows us to exclude the effect of different complex geometries optimized by various methods from the analysis of $E_{\mathrm{int}}$ and $E_{\mathrm{int}}^{\mathrm{CP}}$. It is so because for each value of the $d$ parameter the same complex geometry was used by both the DFT methods and CCSD(T) for calculating $E_{\text {int }}$ and $E_{\text {int }}^{\mathrm{CP}}$. Figure 5 presents the exemplary plots of $E_{\text {int }}^{\mathrm{CP}}$ as a function of $d$ in $\mathrm{SnH}_{2}$-benzene and $\mathrm{SnH}_{2}$ pyridine for 14 DFT methods combined with the aug-ccpVTZ basis set. For clarity, the DFT methods are divided into two groups, without and with the dispersion correction. It is evident from Fig. 5 that BP86, BLYP, TPSS, B3LYP, B98, and TPSSh underestimate the strength of the interaction in the $\pi$ complex in the whole range of $d$ values. By contrast, $\omega \mathrm{B} 97 \mathrm{X}$ and M11 slightly overestimate the binding around the minimum region in this complex but their curves of $E_{\text {int }}^{\mathrm{CP}}$ are generally much closer to the $\operatorname{CCSD}(\mathrm{T})$ curve than those obtained by six non-RSH standard density functionals. The comparison of two plots on the left-hand side in Fig. 5 reveals that the addition of the dispersion correction systematically lowers $E_{\text {int }}^{\mathrm{CP}}$ toward more negative values. However, it becomes apparent that the addition of the dispersion correction not only compensates for the $E_{\text {int }}^{\mathrm{CP}}$ underestimation typical of the non-RSH standard density functionals but, unfortunately, leads to some overestimation of $E_{\text {int }}^{\mathrm{CP}}$ in the minimum region. The TPSS-D density functional demonstrates the most significant overestimation in this region. A severe overestimation of interaction energies by TPSS in conjunction with Grimme's dispersion correction was also detected for the complexes of benzene with main group [44] and transition metal atoms [73]. The dispersion-corrected density functionals provide a much better description of the interaction for very large $d$ values $(d>4.5 \AA)$ in the $\pi$-complex. Among the density functionals without the dispersion correction, $\omega \mathrm{B} 97 \mathrm{X}$ and M11 produce the $E_{\mathrm{int}}^{\mathrm{CP}}$ curves that are the closest to the $\operatorname{CCSD}(\mathrm{T})$ one also for the $\sigma$-complex. With the values of $d$ ranging in the $3-4 \AA$ interval, $\omega B 97 X$ overestimates the interaction between $\mathrm{SnH}_{2}$ and pyridine slightly, whereas M11 exhibits the underestimation of $E_{\text {int }}^{\mathrm{CP}}$ It is rather of secondary importance to practical calculations that the slope of the $E_{\text {int }}^{\mathrm{CP}}$ curves for small $d$ values $(d<$ $2.1 \AA$ ) is significantly less steep for the DFT methods than for $\operatorname{CCSD}(\mathrm{T})$. The $E_{\text {int }}^{\mathrm{CP}}$ curves of the DFT methods incorporating the dispersion correction differ from the $\operatorname{CCSD}(\mathrm{T})$ curve of $E_{\text {int }}^{\text {CP }}$ marginally. Only the TPSS-D density functional exhibits an exceptional behavior in the minimum region where a significant overbinding of $\mathrm{SnH}_{2}$ by pyridine is predicted with use of this functional. The comparison of the bottom plots in Fig. 5 also indicates that if the dispersion correction is introduced to BP86, BLYP, B3LYP, B98, and $\omega$ B97X, then the reproduction of the reference $E_{\text {int }}^{\mathrm{CP}}$ curve is more effective for the $\sigma$ complex than for the $\pi$-complex.

In order to facilitate the quantitative evaluation of the performance of the DFT methods in reproducing the CCSD(T) curves of $E_{\text {int }}$ and $E_{\text {int }}^{\mathrm{CP}}$ in $\mathrm{SnH}_{2}$-benzene and $\mathrm{SnH}_{2}$-pyridine, the values of MSE and RMSE in $E_{\text {int }}$ and $E_{\text {int }}^{\mathrm{CP}}$ for the curves obtained by each density functional were determined. Table 7 gathers the values of MSE and RMSE in $E_{\text {int }}$ and $E_{\text {int }}^{\mathrm{CP}}$ calculated by 14 DFT methods in conjunction with the aug-cc-pVTZ basis set (results for the remaining three basis sets are given in Tables S16-S18, see Electronic supplementary material). A survey of the tabulated results clearly shows that the performance of the DFT methods is largely affected by the presence of counterpoise correction in the interaction energy, the type of complexation and the choice of basis set. We will discuss the errors in $E_{\text {int }}$ first. When the def2-TZVP and cc-pVTZ basis sets are taken into consideration, the $\operatorname{CCSD}(\mathrm{T})$ curves of $E_{\text {int }}$ are reproduced best by the M11 density functional (see the respective values of RMSE in Tables S16 and S18). The augmentation of these basis sets with their sets of diffuse functions leads to a loss in accuracy for M11 and the combinations of BP86-D and TPSS-D with def2-TZVPD or aug-cc-pVTZ produce the $E_{\text {int }}$ curves that are most consistent with the reference curves. The values of RMSE for M11/def2-TZVPD and M11/ aug-cc-pVTZ indicate that the performance of M11 is close to that of BLYP-D, B3LYP-D, and B97-D. These dispersioncorrected density functionals perform considerably worse than BP86-D and TPSS-D. Although the addition of the dispersion correction to $\omega \mathrm{B} 97 \mathrm{X}$ may result in a modest increase in RMSE, the density functionals investigated here generally benefit from the inclusion of such a correction. The values of MSE in $E_{\text {int }}$ in Table 7 are all positive, which means that the DFT 

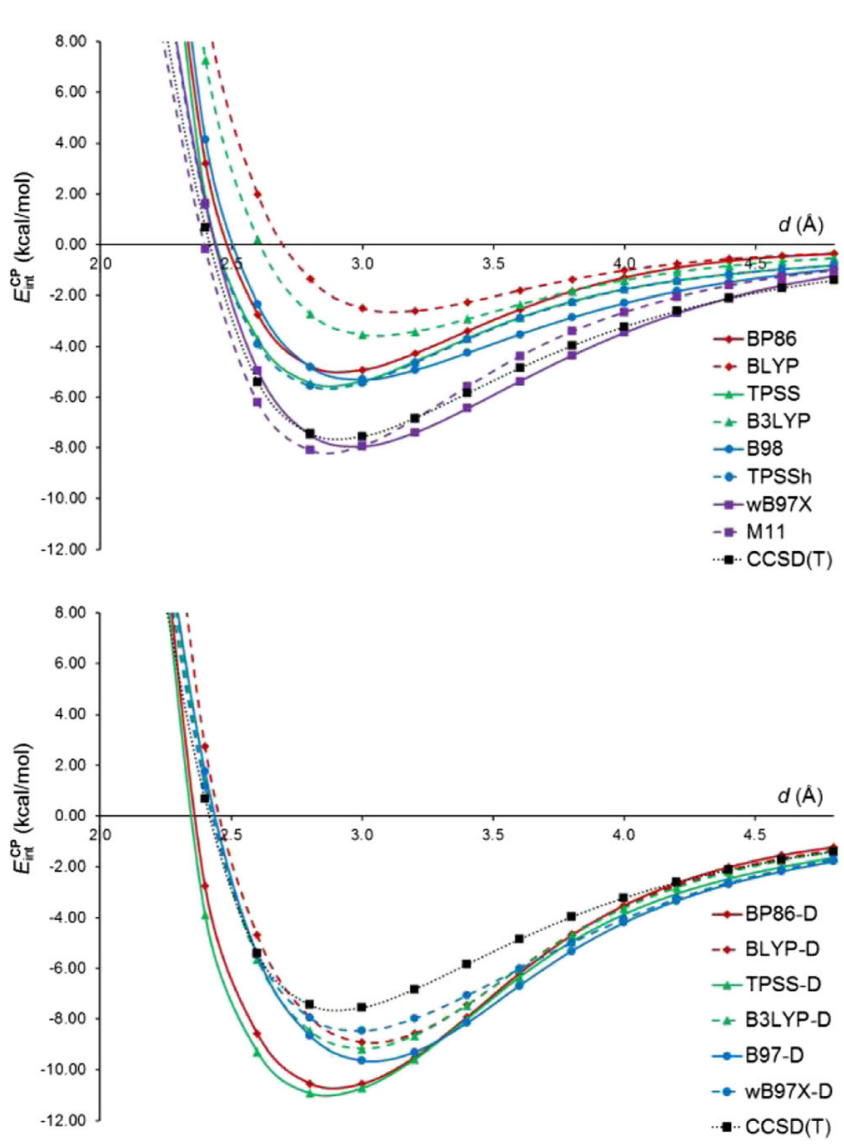

Fig. $5 E_{\text {int }}^{\mathrm{CP}}$ for the $\pi$-complex of $\mathrm{SnH}_{2}$ with benzene (left) and the $\sigma$ complex of $\mathrm{SnH}_{2}$ with pyridine (right) as a function of the geometrical parameter $d$. Fourteen DFT methods were combined with the aug-cc-

curves tend to be placed above the $\operatorname{CSSD}(\mathrm{T})$ curve on the axis of $E_{\text {int }}$. For the remaining basis sets there is, however, no such regularity in the position of the DFT curves. In the case of $E_{\text {int }}^{\mathrm{CP}}$, the performance of the DFT methods in reproducing the $\operatorname{CCSD}(\mathrm{T})$ curves changes with the type of complexation. For the $\pi$-complex, the $\omega \mathrm{B} 97 \mathrm{X}$ density functional affords the best agreement with the $\operatorname{CCSD}(\mathrm{T})$ curve of $E_{\mathrm{int}}^{\mathrm{CP}} \omega \mathrm{B} 97 \mathrm{X}$ is followed by M11 irrespective of the basis set employed. Among the nonRSH standard density functionals, TPSS and TPSSh seem to be the most suitable for the reliable determination of the $E_{\text {int }}^{\mathrm{CP}}$ curve in the $\pi$-complex. Slightly larger values of RMSD occur for such dispersion-corrected density functionals as BP86-D, BLYP-D, B3LYP-D, and B97-D. The reference curve of $E_{\text {int }}^{\mathrm{CP}}$ in the $\sigma$-complex is mimicked best by M11 if this density functional is used together with aug-cc-pVTZ. The application of the other basis sets favors TPSS and TPSSh. As indicated by the values of MSE in $E_{\text {int }}^{\mathrm{CP}}$, these two functionals have a tendency to compute a weaker interaction between $\mathrm{SnH}_{2}$ and pyridine across the investigated range of the $d$ parameter in comparison to the interaction predicted by $\operatorname{CCSD}(\mathrm{T})$. Introducing the dispersion correction to BLYP and B3LYP always leads to a substantial improvement in reproducing the reference $E_{\text {int }}^{\mathrm{CP}}$ curve for the $\sigma$-complex. However, the other density functionals do
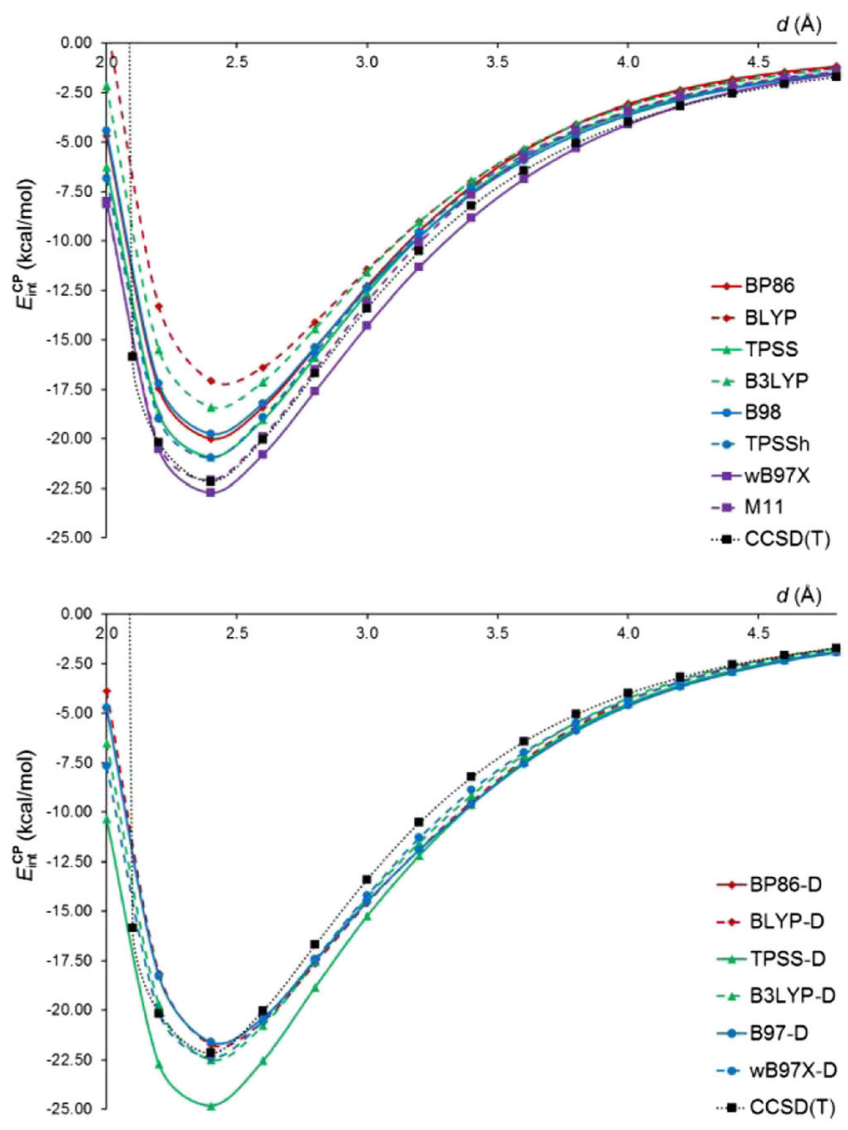

pVTZ basis set. The $E_{\text {int }}^{\mathrm{CP}}$ curves obtained at the $\operatorname{CCSD}(\mathrm{T}) /$ aug-cc-pVTZ level are also shown for comparison

not necessarily exhibit a decrease in RMSE and a change of MSE to zero when they are used with the dispersion correction. In consequence, one can postulate that the application of the dispersion correction to the density functional that as such yields good agreement with the reference $E_{\mathrm{int}}^{\mathrm{CP}}$ curve for the $\sigma$ complex is inefficient.

In order to gain additional insight into the quality of the interaction energy curves reproduced by the DFT methods, it is helpful to situate their performances in a ranking covering both the DFT and the MP2-type methods. The comparison of MSE and RMSE in $E_{\text {int }}$ and $E_{\text {int }}^{\mathrm{CP}}$ obtained by the DFT and MP2-type methods indicates that the SCS-MP2 method reproduces the reference interaction energy curves with the greatest accuracy and its performance is practically independent of the choice of basis set. In contrast to the nearly constant performance of SCS-MP2, the errors determined for the DFT methods are in several cases smaller (e.g., $\operatorname{MSE}\left(E_{\text {int }}\right)$ of $\omega \mathrm{B} 97 \mathrm{X}$ for $\mathrm{SnH}_{2}$-pyridine) but mostly larger than those of SCS-MP2. On this basis it can be concluded that even the best performing density functionals, that is, the RSH ones and those incorporating the dispersion correction, cannot compete with SCS-MP2. On the other hand, they are superior to the conventional MP2 method. 
Table 7 MSE and RMSE in $E_{\text {int }}$ and $E_{\text {int }}^{\mathrm{CP}}$ across the interaction energy curves for the $\mathrm{SnH}_{2}$-benzene and $\mathrm{SnH}_{2}$-pyridine complexes

\begin{tabular}{|c|c|c|c|c|c|c|c|c|}
\hline \multirow[t]{3}{*}{ Method } & \multicolumn{4}{|c|}{$\mathrm{SnH}_{2}$-benzene } & \multicolumn{4}{|c|}{$\mathrm{SnH}_{2}$-pyridine } \\
\hline & \multicolumn{2}{|l|}{$E_{\text {int }}$} & \multicolumn{2}{|l|}{$E_{\mathrm{int}}^{\mathrm{CP}}$} & \multicolumn{2}{|l|}{$E_{\text {int }}$} & \multicolumn{2}{|l|}{$E_{\mathrm{int}}^{\mathrm{CP}}$} \\
\hline & MSE & RMSE & MSE & RMSE & MSE & RMSE & MSE & RMSE \\
\hline BP86 & 4.26 & 4.72 & 2.11 & 2.18 & 2.97 & 3.53 & 1.24 & 1.37 \\
\hline BP86-D & 0.66 & 0.91 & -1.49 & 2.04 & 0.76 & 1.16 & -0.97 & 1.25 \\
\hline BLYP & 5.92 & 7.11 & 3.76 & 4.45 & 3.86 & 5.01 & 2.13 & 2.85 \\
\hline BLYP-D & 1.81 & 2.83 & -0.35 & 1.06 & 1.34 & 2.38 & -0.39 & 0.95 \\
\hline TPSS & 3.74 & 4.17 & 1.55 & 1.64 & 2.48 & 3.00 & 0.73 & 0.80 \\
\hline TPSS-D & 0.31 & 0.48 & -1.88 & 2.39 & 0.38 & 0.76 & -1.37 & 1.63 \\
\hline B3LYP & 5.15 & 6.12 & 2.96 & 3.44 & 3.51 & 4.37 & 1.76 & 2.17 \\
\hline B3LYP-D & 1.55 & 2.34 & -0.64 & 0.96 & 1.30 & 1.97 & -0.44 & 0.61 \\
\hline B98 & 3.78 & 4.55 & 1.59 & 1.86 & 2.76 & 3.53 & 1.00 & 1.32 \\
\hline B97-D & 1.14 & 2.36 & -1.03 & 1.41 & 1.26 & 2.39 & -0.48 & 0.97 \\
\hline TPSSh & 3.67 & 4.08 & 1.48 & 1.58 & 2.58 & 3.04 & 0.81 & 0.87 \\
\hline$\omega B 97 X$ & 2.05 & 2.73 & -0.09 & 0.44 & 1.30 & 1.77 & -0.41 & 0.54 \\
\hline$\omega B 97 X-D$ & 1.53 & 2.42 & -0.63 & 0.80 & 1.32 & 1.93 & -0.42 & 0.49 \\
\hline M11 & 2.01 & 2.22 & 0.08 & 0.55 & 2.00 & 2.28 & 0.36 & 0.43 \\
\hline
\end{tabular}

The errors are calculated for the interaction energies obtained from 14 DFT methods combined with the aug-cc-pVTZ basis set with respect to the CCSD(T)/aug-cc-pVTZ energies

All values in $\mathrm{kcal} \mathrm{mol}^{-1}$

Having evaluated the performance of the DFT methods in reproducing the structure and energetics of the $\mathrm{SnH}_{2}$-benzene and $\mathrm{SnH}_{2}$-pyridine complexes, we extended the set of investigated complexes in order to test the transferability of the findings made in the previous paragraphs. In consequence, the performance of 14 DFT methods was reassessed using a test set containing five $\pi$-complexes of $\mathrm{SnX}_{2}$ with benzene (where $\mathrm{X}=\mathrm{H}, \mathrm{F}, \mathrm{Cl}, \mathrm{Br}, \mathrm{I}$ ) and five $\sigma$-complexes of $\mathrm{SnX}_{2}$ with pyridine. We did not manage to obtain the reference structures of $\mathrm{SnX}_{2}$-benzene and $\mathrm{SnX}_{2}$-pyridine $(\mathrm{X}=\mathrm{F}, \mathrm{Cl}, \mathrm{Br}, \mathrm{I})$ at the CCSD level of theory because performing the respective geometry optimizations far exceeded the computational resources available to us. Hence, we employed less computationally demanding methods to produce the reference structures for the whole set of complexes. We obviously made use of the conclusions drawn in the previous section and, therefore, SOS-MP2 was selected for obtaining the reference geometries of the $\pi$-complexes whereas SCS-MP2 provided the reference geometries of the $\sigma$-complexes. As we remember, for $\mathrm{SnH}_{2}$-benzene and $\mathrm{SnH}_{2}$-pyridine these two MP2-type methods produced the values of RMSD that were very close to those of CCSD and simultaneously much smaller than those of the DFT methods. Next, the geometries of additional eight complexes of stannylenes containing halogen atoms were optimized using 14 DFT methods. Table 8 summarizes the most important structural and energetic properties of all ten complexes investigated at the $\omega$ B97X/aug-cc-pVTZ level of theory. From the results in this table, we see that the complexations of benzene and pyridine by the stannylenes containing halogen atoms are essentially similar to the corresponding complexations by $\mathrm{SnH}_{2}$. The structures of the complexes with the stannylenes containing halogen atoms are not far different from the structures of the complexes with $\mathrm{SnH}_{2}$ and the differences in the interaction energies between the complexes with $\mathrm{X}$ being a halogen atom and the complexes with $\mathrm{X}=\mathrm{H}$ do not exceed $1.20 \mathrm{kcal} \mathrm{mol}^{-1}$. The $d$ distance changes monotonously in both types of complexes with $\mathrm{X}$ being a halogen atom. Unsurprisingly, this distance elongates when $\mathrm{X}$ gets heavier. It is interesting to note that, in contrast to $\mathrm{SnH}_{2}$-benzene, the $\pi$-complexes with the halogenated stannylenes exhibit a slight shift of the Sn atom toward the center of the benzene ring $\left(a_{1}>90^{\circ}\right)$. The counterpoise correction for the BSSE is small for the DFT methods. In the case of $\omega \mathrm{B} 97 \mathrm{X} / \mathrm{aug}-\mathrm{cc}-\mathrm{pVTZ}$ this correction weakens the interaction in the $\sigma$-complexes by $0.5 \mathrm{kcal} \mathrm{mol}^{-1}$ at the most. The effect of the counterpoise correction on the strength of the interaction in the $\pi$-complexes is even smaller.

The structures of the ten complexes optimized by the DFT methods were compared with the corresponding reference structures. For each DFT method combined with a given basis set, the value of RMSD was calculated for each complex and ten resulting RMSD values were averaged in order to express the quality of predicted structures with a single quantity. Figure 6 presents the average values of RMSD for 14 DFT methods and four basis sets. Of the DFT methods without the empirical dispersion correction, $\omega \mathrm{B} 97 \mathrm{X}$ and M11 are 
Table 8 Selected geometrical $\left(d, a_{1}\right.$, and $\left.a_{2}\right)$ and energetic $\left(E_{\text {int }}\right.$ and $\left.E_{\text {int }}^{\mathrm{CP}}\right)$ parameters for five $\pi$-complexes of SnX $\mathrm{X}_{2}$ with benzene and five $\sigma$-complexes of $\mathrm{SnX}_{2}$ with pyridine calculated at the $\omega \mathrm{B} 97 \mathrm{X} /$ aug-cc-pVTZ level of theory

\begin{tabular}{|c|c|c|c|c|c|c|c|c|c|c|}
\hline \multirow[t]{2}{*}{$\mathrm{X}$} & \multicolumn{5}{|c|}{$\mathrm{SnX}_{2}$-benzene } & \multicolumn{5}{|c|}{$\mathrm{SnX}_{2}$-pyridine } \\
\hline & $d$ & $a_{1}$ & $a_{2}$ & $E_{\mathrm{int}}$ & $E_{\mathrm{int}}^{\mathrm{CP}}$ & $d$ & $a_{1}$ & $a_{2}$ & $E_{\text {int }}$ & $E_{\mathrm{int}}^{\mathrm{CP}}$ \\
\hline $\mathrm{H}$ & 2.919 & 88.19 & 16.11 & -9.38 & -9.28 & 2.380 & 120.24 & 5.81 & -24.07 & -23.83 \\
\hline $\mathrm{F}$ & 2.998 & 95.89 & 5.88 & -9.81 & -9.68 & 2.366 & 125.11 & 14.51 & -24.78 & -24.28 \\
\hline $\mathrm{Cl}$ & 3.029 & 95.81 & 1.15 & -9.67 & -9.71 & 2.374 & 120.30 & 4.07 & -25.20 & -24.85 \\
\hline $\mathrm{Br}$ & 3.050 & 96.17 & 3.96 & -9.45 & -9.51 & 2.382 & 119.32 & 1.52 & -24.95 & -24.57 \\
\hline I & 3.076 & 96.23 & 6.83 & -9.00 & -9.10 & 2.387 & 118.01 & 1.84 & -24.27 & -23.93 \\
\hline
\end{tabular}

Distances in $\AA$, angles in ${ }^{\circ}$, and energies in $\mathrm{kcal} \mathrm{mol}^{-1}$

particularly efficient in predicting the structures of the $\pi$ - and $\sigma$ complexes. These density functionals are followed by TPSSh. The inclusion of the dispersion correction to the older density functionals is beneficial, although for BLYP-D its average RMSD value as such still remains large. The comparison of the average RMSD values produced by B98 and B97-D may suggest that the dispersion correction deteriorates the performance of B98. It is not true because in the case of B97-D the effect of the dispersion correction is eliminated by the absence of the HF exchange (while B98 incorporates the HF exchange into its exchange part). The inclusion of the HF exchange leads to a substantial improvement in the agreement with the reference structures, which is indicated by the smaller average RMSD values for B3LYP and TPSSh in juxtaposition with the average RMSD values of BLYP and TPSS, respectively. It is consistent with the findings made previously in this section for the reproduction of the $\mathrm{SnH}_{2}$-benzene and $\mathrm{SnH}_{2}$-pyridine structures. Overall, the performance of the DFT methods in reproducing the structures of $\mathrm{SnH}_{2}$-benzene and $\mathrm{SnH}_{2}$-pyridine turns out to be transferable to our more representative set of the complexes of simple stannylenes with aromatic molecules. From the current results and from what we have recently demonstrated for trimethyltin cyanide dimer [91], it can be deduced that the $\omega \mathrm{B} 97 \mathrm{X}$ and M11 density functionals generally show excellent performance in predicting structures of systems with weak interactions involving tin.

The next step is to assess the performance of 14 DFT methods using their values of $\operatorname{MSE}\left(E_{\text {int }}^{\mathrm{CP}}\right)$ and $\operatorname{RMSE}\left(E_{\text {int }}^{\mathrm{CP}}\right)$ with respect to the $E_{\text {int }}^{\mathrm{CP}}$ values predicted by $\operatorname{CCSD}(\mathrm{T})$. Each DFT method was employed to calculate $E_{\text {int }}^{\mathrm{CP}}$ for the structures optimized previously by the same method. The $\operatorname{CCSD}(\mathrm{T})$ values of $E_{\text {int }}^{\mathrm{CP}}$ were determined for five $\pi$ complexes optimized by SOS-MP2 and five $\sigma$-complexes optimized by SCS-MP2. Each value of $\operatorname{MSE}\left(E_{\text {int }}^{\mathrm{CP}}\right)$ or $\operatorname{RMSE}\left(E_{\text {int }}^{\mathrm{CP}}\right)$ was obtained from the calculations utilizing the same basis set. Figure 7 depicts the values of $\operatorname{MSE}\left(E_{\text {int }}^{\mathrm{CP}}\right)$ and $\operatorname{RMSE}\left(E_{\text {int }}^{\mathrm{CP}}\right)$ for 14 DFT methods in combination with four basis sets. As is seen in the left-hand plot in Fig. 7, non-RSH standard density functionals yield positive $\operatorname{MSE}\left(E_{\text {int }}^{\mathrm{CP}}\right)$, which means that the $\mathrm{SnX}_{2}$ stannylenes are generally underbound by benzene and pyridine. In contrast to the non-RSH standard density functionals, those utilizing the range separation and/ or the dispersion correction tend to overestimate the strength of the interaction between $\mathrm{SnX}_{2}$ and benzene/pyridine. Also
Fig. 6 Average RMSD for ten complexes of $\mathrm{SnX}_{2}(\mathrm{X}=\mathrm{H}, \mathrm{F}, \mathrm{Cl}$, $\mathrm{Br}$, I) with benzene or pyridine obtained by 14 DFT methods in combination with four basis sets

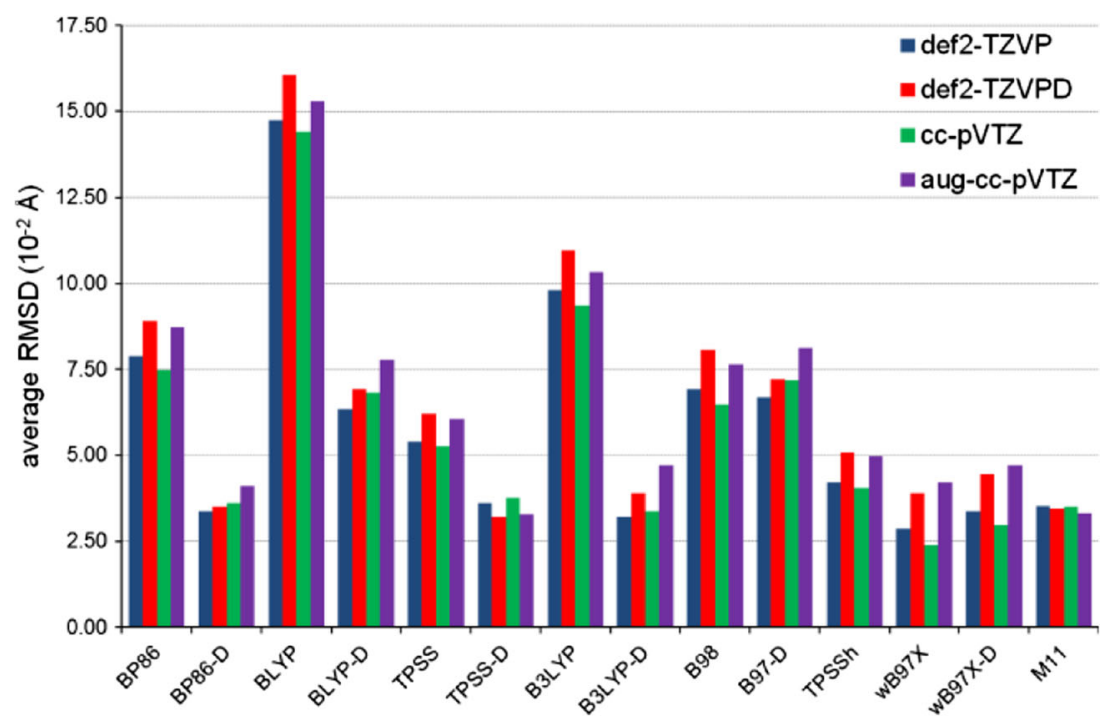



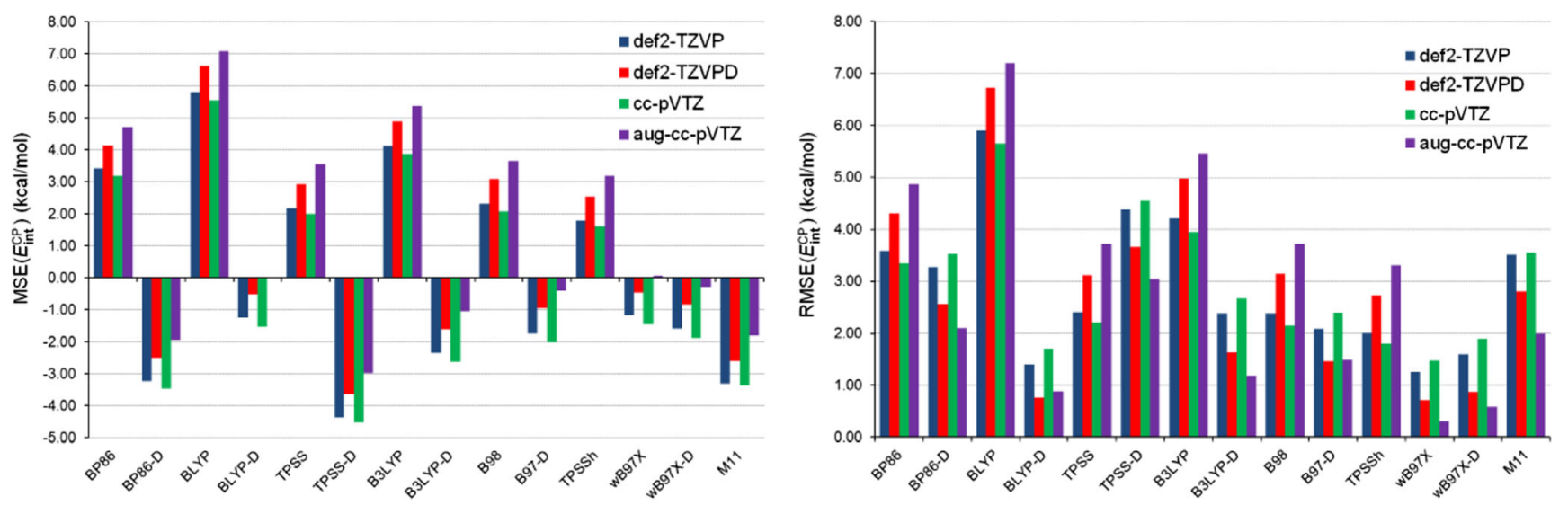

Fig. 7 MSE and RMSE in $E_{\text {int }}^{\mathrm{CP}}$ obtained by 14 DFT methods in combination with four basis sets with respect to the CCSD(T) results

apparent from the left-hand plot in Fig. 7 is the fact that BLYP-D and $\omega$ B97X in conjunction with aug-cc-pVTZ produce negligible $\operatorname{MSE}\left(E_{\text {int }}^{\mathrm{CP}}\right)$. These two methods, as well as the $\omega \mathrm{B} 97 \mathrm{X}-\mathrm{D}$ one, afford the best agreements with the $\operatorname{CCSD}(\mathrm{T})$ results when $\operatorname{RMSE}\left(E_{\text {int }}^{\mathrm{CP}}\right)$ is considered. Admittedly, for these methods their $\operatorname{RMSE}\left(E_{\text {int }}^{\mathrm{CP}}\right)$ values are strongly dependent on the basis set employed, but they are always lower than $2.00 \mathrm{kcal} \mathrm{mol}^{-1}$. One should, however, remember that the BLYP-D values of $E_{\text {int }}^{\mathrm{CP}}$ were calculated for the corresponding optimized geometries that were noticeably different from the reference ones. The opposite situation occurs for $\omega$ B97X and $\omega$ B97X-D where good geometries correlate with good $E_{\text {int }}^{\mathrm{CP}}$ values. The extension of the test set of complexes does not change the main findings made previously for $E_{\text {int }}^{\mathrm{CP}}$ in $\mathrm{SnH}_{2}$-benzene and $\mathrm{SnH}_{2}$-pyridine. In particular, the excellent performance of $\omega \mathrm{B} 97 \mathrm{X}$ in reproducing $E_{\mathrm{int}}^{\mathrm{CP}}$ is confirmed for the set of the $\mathrm{SnX}_{2}$-benzene and $\mathrm{SnX}_{2}$-pyridine complexes. On the other hand, M11 performs worse for $E_{\text {int }}^{\mathrm{CP}}$ in this set compared to its performance for $E_{\text {int }}^{\mathrm{CP}}$ in $\mathrm{SnH}_{2}$ benzene and $\mathrm{SnH}_{2}$-pyridine.

The results presented in Fig. 7 indicate that the performance of individual DFT methods is sensitive to the choice of basis set and an overall assessment of individual DFT methods may sometimes be ambiguous when all four basis sets are taken into consideration. It is mainly due to the fact that our evaluation procedure is based on a comparison to the reference $\operatorname{CCSD}(\mathrm{T})$ results obtained with the same triple- $\zeta$, basis sets as those combined with the DFT methods. The application of more extended basis sets would undoubtedly be advisable but then the computational cost would become prohibitively expensive. Nevertheless, we have tried to carry out an additional performance assessment of the DFT methods in predicting $E_{\text {int }}$ and $E_{\text {int }}^{\mathrm{CP}}$, and in this study we compare the DFT results to the interaction energies obtained from SCSMP2 in conjunction with an extrapolation to the complete basis set (CBS) limit (details of the SCS-MP2/CBS calculations are described in section S2, see Electronic supplementary material). The SCS-MP2/CBS determination of the interaction energy in $\mathrm{SnX}_{2}$-benzene and $\mathrm{SnX}_{2}$-pyridine constituted the highest-quality calculations that were feasible for the computer system available to us. Figure 8 shows $\operatorname{RMSE}\left(E_{\text {int }}\right)$ and $\operatorname{RMSE}\left(E_{\text {int }}^{\mathrm{CP}}\right)$ with respect to the SCS-MP2/CBS results. Immediately apparent are the marked differences in the values of errors between six non-RSH standard density functionals and the other density functionals. The non-RSH standard density functionals yield $\operatorname{RMSE}\left(E_{\text {int }}\right)$ and $\operatorname{RMSE}\left(E_{\text {int }}^{\mathrm{CP}}\right)$ in the range
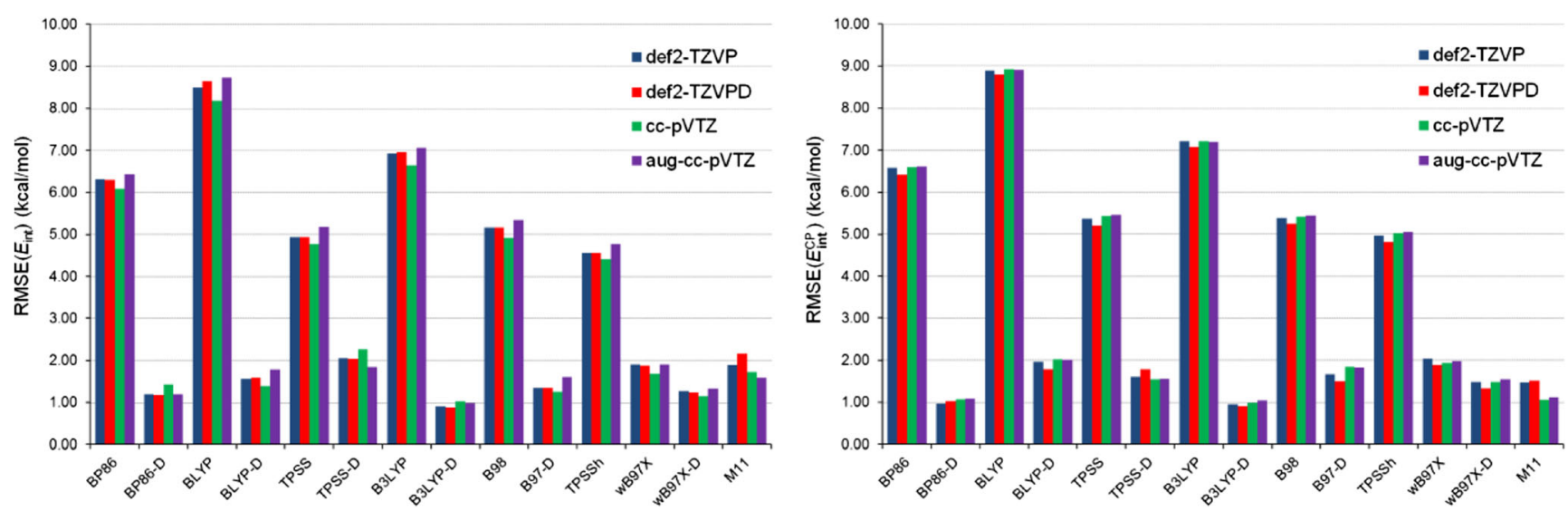

Fig. 8 RMSE in $E_{\text {int }}$ and $E_{\text {int }}^{\mathrm{CP}}$ obtained by 14 DFT methods in combination with four basis sets with respect to the SCS-MP2/CBS results 
from 4.00 to $9.00 \mathrm{kcal} \mathrm{mol}^{-1}$, whereas the RSH and dispersion-corrected density functionals exhibit much lower values of these errors. The performances of the RSH and dispersion-corrected density functionals are actually comparable: their values of errors vary by ca. $1 \mathrm{kcal} \mathrm{mol}^{-1}$ at the most. It is also seen from Fig. 8 that there is a considerable reduction of the basis set effect for each DFT method.

\section{Conclusions}

In this work the performances of six MP2-type methods (MP2, SCS-MP2, SOS-MP2, FE2-MP2, SCS(MI)-MP2, and S2-MP2), eight standard density functionals (BP86, BLYP, TPSS, B3LYP, B98, TPSSh, $\omega B$ 97X, and M11) and their six combinations with an empirical dispersion correction (BP86-D, BLYP-D, TPSS-D, B3LYP-D, B97-D, and $\omega B 97 X-D)$ were assessed for the purposes of investigating the interaction between stannylenes and aromatic molecules. These methods were used in conjunction with four basis sets of triple- $\zeta$ valence quality (def2-TZVP(P), def2-TZVP(P)D, cc-pVTZ, and aug-cc-pVTZ). Structural and energetic properties of two kinds of complexes were calculated using the aforementioned methods. The first kind of the studied complexes was formed by a $\mathrm{SnX}_{2}$ molecule (where $\mathrm{X}=\mathrm{H}, \mathrm{F}, \mathrm{Cl}$, $\mathrm{Br}, \mathrm{I})$ interacting with the $\pi$-electrons of benzene. The second one encompassed the $\sigma$-complexation of $\mathrm{SnX}_{2}$ by the $\mathrm{N}$-atom lone electron pair of pyridine. The assessment of the aforementioned methods was based on several evaluation procedures comparing the structures and interaction energies predicted by these methods with reference computational data. A very detailed analysis of the performances of the MP2-type and DFT methods was carried out for $\mathrm{SnH}_{2}$-benzene and $\mathrm{SnH}_{2}$-pyridine. The reference structures and interaction energies for these two complexes were obtained from CCSD and $\operatorname{CCSD}(\mathrm{T})$, respectively. The DFT methods were also evaluated using the full test set of $\mathrm{SnX}_{2}$-benzene and $\mathrm{SnX}_{2}$-pyridine complexes but then the reference structures of ten complexes were calculated using the best performing MP2-type methods. Taking into account the results of all evaluation procedures, we make the following findings:

1. Of the MP2-type methods, the reference structure of $\mathrm{SnH}_{2}$ benzene is reproduced best by SOS-MP2, whereas SCSMP2 is capable of mimicking the reference structure of $\mathrm{SnH}_{2}$-pyridine with the greatest accuracy. The latter method performs best in predicting the interaction energy between $\mathrm{SnH}_{2}$ and benzene and between $\mathrm{SnH}_{2}$ and pyridine.

2. Among the DFT methods, $\omega \mathrm{B} 97 \mathrm{X}$ and M11 provide the structures and interaction energies of the $\mathrm{SnH}_{2}$-benzene and $\mathrm{SnH}_{2}$-pyridine complexes with good accuracy. Their performances in reproducing the interaction energies are, however, sensitive to the choice of specific triple- $\zeta$ basis set.
3. The best performing MP2-type methods are generally better than the DFT methods in reproducing the structures and interaction energies for $\mathrm{SnH}_{2}$-benzene and $\mathrm{SnH}_{2}$-pyridine. On the other hand, the RSH density functionals and many dispersion-corrected density functionals are often superior to the conventional MP2 method.

4. The evaluation procedure taking five $\pi$-complexes and five $\sigma$-complexes into account confirms that $\omega \mathrm{B} 97 \mathrm{X}$, M11, BP86-D, and TPSS-D are particularly efficient in predicting the structures of these complexes. The good geometries predicted by $\omega \mathrm{B} 97 \mathrm{X}$ correlate with its good $E_{\text {int }}^{\mathrm{CP}}$ values. The comparison of $E_{\text {int }}$ and $E_{\mathrm{int}}^{\mathrm{CP}}$ calculated by 14 DFT methods with the SCS-MP2/CBS results indicates that the levels of accuracy provided by the RSH and the dispersion-corrected density functionals do not differ significantly: the RMSE differences between these density functionals do not exceed $1-2 \mathrm{kcal} \mathrm{mol}^{-1}$.

We hope that these findings will provide a guide for the reliable computational investigations of the interaction between stannylenes and aromatic molecules.

Acknowledgments The calculations using TURBOMOLE and GAUSSIAN were carried out in Wrocław Center for Networking and Supercomputing and in the Academic Computer Center CYFRONET of the AGH University of Science and Technology in Cracow. This work was also partially supported by PL-Grid Infrastructure.

Open Access This article is distributed under the terms of the Creative Commons Attribution License which permits any use, distribution, and reproduction in any medium, provided the original author(s) and the source are credited.

\section{References}

1. Koch W, Holthausen MC (2001) A chemist's guide to density functional theory, 2nd edn. Wiley-VCH, Weinheim

2. Parr RG, Yang W (1989) Density-functional theory of atoms and molecules. Oxford University Press, New York

3. Mori-Sánchez P, Cohen AJ, Yang W (2006) Many-electron self-interaction error in approximate density functionals. J Chem Phys 125: 201102

4. Dutoi AD, Head-Gordon M (2006) Self-interaction error of local density functionals for alkali-halide dissociation. Chem Phys Lett 422:230-233

5. Klimeš J, Michaelides A (2012) Advances and challenges in treating van der Waals dispersion forces in density functional theory. J Chem Phys 137:120901

6. Jiménez-Hoyos CA, Janesko BG, Scuseria GE (2009) Evaluation of range-separated hybrid and other density functional approaches on test sets relevant for transition metal-based homogeneous catalysts. J Phys Chem A 113:11742-11749

7. Kulkarni AD, Truhlar DG (2011) Performance of density functional theory and Møller-Plesset second-order perturbation theory for 
structural parameters in complexes of Ru. J Chem Theory Comput 7: 2325-2332

8. Minenkov Y, Singstad Å, Occhipinti G, Jensen VR (2012) The accuracy of DFT-optimized geometries of functional transition metal compounds: a validation study of catalysts for olefin metathesis and other reactions in the homogeneous phase. Dalton Trans 41:5526-5541

9. Ignatyev IS, Montejo M, López González JJ (2013) An assessment of DFT methods for predicting the thermochemistry of ion-molecule reactions of group 14 elements (Si, Ge, Sn). J Mol Model 19:5439-5444

10. Bernardo CEP, Bauman NP, Piecuch P, Silva PJ (2013) Evaluation of density functional methods on the geometric and energetic descriptions of species involved in $\mathrm{Cu}^{+}$-promoted catalysis. J Mol Model 19: 5457-5467

11. Møller C, Plesset MS (1934) Note on an approximation treatment for many-electron systems. Phys Rev 46:618-622

12. Cybulski SM, Chałasiński G, Moszyński R (1990) On decomposition of second-order Møller-Plesset supermolecular interaction energy and basis set effects. J Chem Phys 92:4357-4363

13. Cybulski SM, Lytle ML (2007) The origin of deficiency of the supermolecule second-order Møller-Plesset approach for evaluating interaction energies. J Chem Phys 127:141102

14. Grimme S (2003) Improved second-order Møller-Plesset perturbation theory by separate scaling of parallel- and antiparallel-spin pair correlation energies. J Chem Phys 118:9095-9102

15. Marchetti O, Werner H-J (2009) Accurate calculations of intermolecular interaction energies using explicitly correlated coupled cluster wave functions and a dispersion-weighted MP2 method. J Phys Chem A 113:11580-11585

16. Pitonak M, Neogrady P, Cerny J, Grimme S, Hobza P (2009) Scaled MP3 non-covalent interaction energies agree closely with accurate CCSD(T) benchmark data. ChemPhysChem 10:282-289

17. Huang Y, Shao Y, Beran GJO (2013) Accelerating MP2C dispersion corrections for dimers and molecular crystals. J Chem Phys 138: 224112

18. Goldey M, Dutoic A, Head-Gordon M (2013) Attenuated secondorder Møller-Plesset perturbation theory: performance within the aug-cc-pVTZ basis. Phys Chem Chem Phys 15:15869-15875

19. Fink RF (2010) Spin-component-scaled Møller-Plesset (SCS-MP) perturbation theory: a generalization of the MP approach with improved properties. J Chem Phys 133:174113

20. Jung Y, Lochan RC, Dutoi AD, Head-Gordon M (2004) Scaled opposite-spin second order Møller-Plesset correlation energy: an economical electronic structure method. J Chem Phys 121:97939802

21. Hill JG, Platts JA (2007) Spin-component scaling methods for weak and stacking interactions. J Chem Theory Comput 3:80-85

22. Zhao Y, Truhlar DG (2009) Benchmark energetic data in a model system for Grubbs II metathesis catalysis and their use for the development, assessment, and validation of electronic structure methods. J Chem Theory Comput 5:324-333

23. Feyereisen MW, Feller D, Dixon DA (1996) Hydrogen bond energy of the water dimer. J Phys Chem 100:2993-2997

24. Weigend F, Häser M (1997) RI-MP2: First derivatives and global consistency. Theor Chem Accounts 97:331-340

25. Jonas V, Thiel W (1995) Theoretical study of the vibrational spectra of the transition metal carbonyls $\mathrm{M}(\mathrm{CO})_{6}[\mathrm{M}=\mathrm{Cr}, \mathrm{Mo}, \mathrm{W}], \mathrm{M}(\mathrm{CO})_{5}$ $[\mathrm{M}=\mathrm{Fe}, \mathrm{Ru}, \mathrm{Os}]$, and $\mathrm{M}(\mathrm{CO})_{4}[\mathrm{M}=\mathrm{Ni}, \mathrm{Pd}, \mathrm{Pt}]$. J Chem Phys 102: 8474-8484

26. Hyla-Kryspin I, Grimme S (2004) Comprehensive study of the thermochemistry of first-row transition metal compounds by spin component scaled MP2 and MP3 methods. Organometallics 23:5581-5592

27. Piacenza M, Hyla-Kryspin I, Grimme S (2007) A comparative quantum chemical study of the ruthenium catalyzed olefin metathesis. J Comput Chem 28:2275-2285

28. Davies AG (2004) Organotin chemistry, 2nd edn. Wiley-VCH, Weinheim
29. Mizuhata Y, Sasamori T, Tokitoh N (2009) Stable heavier carbene analogues. Chem Rev 109:3479-3511

30. Dove AP, Gibson VC, Marshall EL, White AJP, Williams DJ (2001) A well defined tin(II) initiator for the living polymerisation of lactide. Chem Commun:283-284

31. Dove AP, Gibson VC, Marshall EL, Rzepa HS, White AJP, Williams DJ (2006) Synthetic, structural, mechanistic, and computational studies on single-site beta-diketiminate tin(II) initiators for the polymerization of rac-lactide. J Am Chem Soc 128:9834-9843

32. Su M-D (2004) Theoretical study on the reactivities of stannylene and plumbylene and the origin of their activation barriers. Chem Eur J 10:6073-6084

33. Kassaee MZ, Musavi SM, Ghambarian M (2005) Divalent propargylenic $\mathrm{C}_{2} \mathrm{H}_{2} \mathrm{M}$ group 14 elements: structures and singlettriplet energy splittings $(\mathrm{M}=\mathrm{C}, \mathrm{Si}, \mathrm{Ge}, \mathrm{Sn}$ and $\mathrm{Pb}) . \mathrm{J}$ Mol Struct (THEOCHEM) 731:225-231

34. Kassaee MZ, Arshadi S, Acedy M, Vessally E (2005) Singlet-triplet energy separations in divalent five-membered cyclic conjugated $\mathrm{C}_{5} \mathrm{H}_{3} \mathrm{X}, \mathrm{C}_{4} \mathrm{H}_{3} \mathrm{SiX}, \mathrm{C}_{4} \mathrm{H}_{3} \mathrm{GeX}, \mathrm{C}_{4} \mathrm{H}_{3} \mathrm{SnX}$, and $\mathrm{C}_{4} \mathrm{H}_{3} \mathrm{PbX}(\mathrm{X}=\mathrm{H}, \mathrm{F}$, $\mathrm{Cl}$, and $\mathrm{Br}$ ). J Organomet Chem 690:3427-3439

35. Nechaev MS (2008) New type of reactions of stannylenes with organic azides: theoretical study. J Mol Struct (THEOCHEM) 862:49 52

36. Wang R-H, Su M-D (2009) Density functional theory study of the reactivities of perimidine-based carbene analogues of the group 14 elements. Organometallics 28:4324-4334

37. Wu C-S, Su M-D (2012) Reactivity for boryl(phosphino)carbenyl carbene analogues with group 14 elements $(\mathrm{C}, \mathrm{Si}, \mathrm{Ge}, \mathrm{Sb}$, and $\mathrm{Pb})$ as a heteroatom: a theoretical study. Dalton Trans 41:3253-3265

38. Bundhun A, Ramasami P, Gaspar PP, Schaefer HF III (2012) Stannylenes: structures, electron affinities, ionization energies, and singlet-triplet gaps of $\mathrm{SnX}_{2} / \mathrm{SnXY}$ and $\mathrm{XSnR} / \mathrm{SnR}_{2} / \mathrm{RSnR}^{\prime}$ species (X; Y=H, F, Cl, Br, I, and R; $\mathrm{R}^{\prime}=\mathrm{CH}_{3}, \mathrm{SiH}_{3}, \mathrm{GeH}_{3}, \mathrm{SnH}_{3}$ ). Inorg Chem 51:851-863

39. Boganov SE, Promyslov VM, Faustov VI, Egorov MP, Nefedov OM (2011) Quantum chemical study of interactions of carbenes and their analogs of the $\mathrm{EH}_{2}$ and $\mathrm{EHX}$ types $(\mathrm{E}=\mathrm{Si}, \mathrm{Ge}, \mathrm{Sn} ; \mathrm{X}=\mathrm{F}, \mathrm{Cl}, \mathrm{Br})$ with $\mathrm{HX}$ and $\mathrm{H}_{2}$, respectively: the insertion and substituent exchange reactions. Russ Chem Bull Int Ed 60:2147-2160

40. Schmidbaur H, Schier A (2008) $\pi$-Complexation of post-transition metals by neutral aromatic hydrocarbons: the road from observations in the 19th century to new aspects of supramolecular chemistry. Organometallics 27:2361-2395

41. Braunschweig H, Gehrhus B, Hitchcock PB, Lappert MF (1995) Synthesis and characterisation of $\mathrm{N} \mathrm{N}^{\prime}$-disubstituted 1,2phenylenebis(amido)tin(II) compounds; X-ray structures of 1,2- and of [1,2-(tmeda). Z Anorg Allg Chem 621:1922-1928

42. Broeckaert L, Geerlings P, Růžička A, Willem R, De Proft F (2012) Can aromatic $\pi$-clouds complex divalent germanium and tin compounds? A DFT study. Organometallics 31:1605-1617

43. Broeckaert L, Turek J, Olejník R, Růžička A, Biesemans M, Geerlings P, Willem R, De Proft F (2013) Combined NMR and DFT study on the complexation behavior of Lappert's tin(II) amide. Organometallics 32:2121-2134

44. Hjertenæs E, Andersson S, Koch H (2013) Assessment of density functionals for van der Waals complexes of sodium and benzene. Mol Phys 111:1211-1218

45. Denis PA, Iribarne F (2014) Theoretical investigation on the interaction between beryllium, magnesium and calcium with benzene, coronene, cirumcoronene and graphene. Chem Phys 430:1-6

46. Forni A, Pieraccini S, Rendine S, Sironi M (2014) Halogen bonds with benzene: an assessment of DFT functionals. J Comput Chem 35: 386-394

47. Szabados Á (2006) Theoretical interpretation of Grimme's spincomponent-scaled second order Møller-Plesset theory. J Chem Phys $125: 214105$ 
48. DiStasio RA, Head-Gordon M (2007) Optimized spin-component scaled second-order Møller-Plesset perturbation theory for intermolecular interaction energies. Mol Phys 105:1073-1083

49. Gauss J (1998) Coupled-cluster theory. In: Schleyer PR, Allinger NL, Clark T et al (eds) Encyclopedia of computational chemistry, vol 1. Wiley, Chichester, pp 615-636

50. Mackie ID, DiLabio GA (2011) Approximations to complete basis set-extrapolated, highly correlated non-covalent interaction energies. J Chem Phys 135:134318

51. Remya K, Suresh CH (2013) Which density functional is close to CCSD accuracy to describe geometry and interaction energy of small noncovalent dimers? A benchmark study using Gaussian09. J Comput Chem 34:1341-1353

52. Hobza P, Müller-Dethlefs K (2010) Non-covalent interactions. Theory and experiment. RSC, Cambridge

53. Ahlrichs R, Armbruster MK, Bachorz RA, Bär M, Baron H-P, Bauernschmitt R, Bischoff FASB, Crawford N, Deglmann P, Della Sala F, Diedenhofen M, Ehrig M, Eichkorn K, Elliott S, Furche F, Glöß A, Haase F, Häser M, Hättig C, Hellweg A, Höfener S, Horn H, Huber C, Huniar U, Kattannek M, Klopper W, Köhn A, Kölmel C, Kollwitz M, May K, Nava P, Ochsenfeld C, Öhm H, Pabst M, Patzelt H, Rappoport D, Rubner O, Schäfer A, Schneider U, Sierka M, Tew DP, Treutler O, Unterreiner B, von Arnim M, Weigend F, Weis P, Weiss H, Winter N (2011) TURBOMOLE. 6.3 edn. University of Karlsruhe and Forschungszentrum Karlsruhe GmbH, 1989-2007, TURBOMOLE GmbH, since 2007, Karlsruhe

54. Frisch MJ, Trucks GW, Schlegel HB, Scuseria GE, Robb MA, Cheeseman JR, Scalmani G, Barone V, Mennucci B, Petersson GA, Nakatsuji H, Caricato M, Li X, Hratchian HP, Izmaylov AF, Bloino J, Zheng G, Sonnenberg JL, Hada M, Ehara M, Toyota K, Fukuda R, Hasegawa J, Ishida M, Nakajima T, Honda Y, Kitao O, Nakai H, Vreven T, Montgomery JA Jr, Peralta JE, Ogliaro F, Bearpark M, Heyd JJ, Brothers E, Kudin KN, Staroverov VN, Keith T, Kobayashi R, Normand J, Raghavachari K, Rendell A, Burant JC, Iyengar SS, Tomasi J, Cossi M, Rega N, Millam JM, Klene M, Knox JE, Cross JB, Bakken V, Adamo C, Jaramillo J, Gomperts R, Stratmann RE, Yazyev O, Austin AJ, Cammi R, Pomelli C, Ochterski JW, Martin RL, Morokuma K, Zakrzewski VG, Voth GA, Salvador P, Dannenberg JJ, Dapprich S, Daniels AD, Farkas O, Foresman JB, Ortiz JV, Cioslowski J, Fox DJ (2010) GAUSSIAN 09 C.01. Gaussian Inc, Wallingford

55. Casella G, Ferrante F, Saielli G (2008) DFT calculation of ${ }^{1} \mathrm{~J}\left({ }^{119} \mathrm{Sn},{ }^{13} \mathrm{C}\right)$ and ${ }^{2} \mathrm{~J}\left({ }^{119} \mathrm{Sn},{ }^{1} \mathrm{H}\right)$ coupling constants in di- and trimethyltin(IV) compounds. Inorg Chem 47:4796-4807

56. Matczak P (2010) Quantum-chemical calculations of spectroscopic, electric and thermochemical properties of some n-butyltin compounds. J Mol Struct (THEOCHEM) 950:83-92

57. Malkin E, Komorovsky S, Repisky M, Demissie TB, Ruud K (2013) The absolute shielding constants of heavy nuclei: resolving the enigma of the ${ }^{119} \mathrm{Sn}$ absolute shielding. J Phys Chem Lett 4:459-463

58. Grimme S (2006) Semiempirical GGA-type density functional constructed with a long-range dispersion correction. J Comput Chem 27: 1787-1799

59. Chai J-D, Head-Gordon M (2008) Systematic optimization of longrange corrected hybrid density functionals. J Chem Phys 128:084106

60. Frisch MJ, Trucks GW, Schlegel HB, Scuseria GE, Robb MA, Cheeseman JR, Scalmani G, Barone V, Mennucci B, Petersson GA, Nakatsuji H, Caricato M, Li X, Hratchian HP, Izmaylov AF, Bloino J, Zheng G, Sonnenberg JL, Hada M, Ehara M, Toyota K, Fukuda R, Hasegawa J, Ishida M, Nakajima T, Honda Y, Kitao O, Nakai H, Vreven T, Montgomery JA Jr, Peralta JE, Ogliaro F, Bearpark M, Heyd JJ, Brothers E, Kudin KN, Staroverov VN, Keith T, Kobayashi R, Normand J, Raghavachari K, Rendell A, Burant JC, Iyengar SS, Tomasi J, Cossi M, Rega N, Millam JM, Klene M, Knox JE, Cross JB, Bakken V, Adamo C, Jaramillo J, Gomperts R, Stratmann RE,
Yazyev O, Austin AJ, Cammi R, Pomelli C, Ochterski JW, Martin RL, Morokuma K, Zakrzewski VG, Voth GA, Salvador P, Dannenberg JJ, Dapprich S, Daniels AD, Farkas O, Foresman JB, Ortiz JV, Cioslowski J, Fox DJ (2013) GAUSSIAN 09 D.01. Gaussian Inc, Wallingford

61. Dunning TH Jr (1989) Gaussian basis sets for use in correlated molecular calculations. I. The atoms boron through neon and hydrogen. J Chem Phys 90:1007-1023

62. Weigend F, Ahlrichs R (2005) Balanced basis sets of split valence, triple zeta valence and quadruple zeta valence quality for $\mathrm{H}$ to $\mathrm{Rn}$ : design and assessment of accuracy. Phys Chem Chem Phys 7:32973305

63. Peterson KA (2003) Systematically convergent basis sets with relativistic pseudopotentials. I. Correlation consistent basis sets for the post-d group 13-15 elements. J Chem Phys 119:11099-11112

64. Rappoport D, Furche F (2010) Property-optimized Gaussian basis sets for molecular response calculations. J Chem Phys 133:134105

65. Boys SF, Bernardi F (1970) The calculation of small molecular interactions by the differences of separate total energies. Some procedures with reduced errors. Mol Phys 19:553-566

66. HYPERCHEM 8.0 (2007). Hypercube Inc, Gainesville

67. Pyykkö P, Xiong X-G, Li J (2011) Aurophilic attractions between a closed-shell molecule and a gold cluster. Faraday Discuss 152:169178

68. Kang R, Chen H, Shaik S, Yao J (2011) Assessment of theoretical methods for complexes of gold(I) and gold(III) with unsaturated aliphatic hydrocarbon: which density functional should we choose? J Chem Theory Comput 7:4002-4011

69. Aquino AAJ, Borges IJ, Nieman R, Köhn A, Lischka H (2014) Intermolecular interactions and charge transfer transitions in aromatic hydrocarbon-tetracyanoethylene complexes. Phys Chem Chem Phys 16:20586-20597

70. Matczak P (2015) Theoretical investigation of the $\mathrm{N} \rightarrow$ Sn coordination in $\left(\mathrm{Me}_{3} \mathrm{SnCN}\right)_{2}$. Struct Chem 26:301-318

71. Papajak E, Zheng J, Xu X, Leverentz HR, Truhlar DG (2011) Perspectives on basis sets beautiful: seasonal plantings of diffuse basis functions. J Chem Theory Comput 7:3027-3034

72. Vijay D, Sakurai H, Sastry GN (2011) The impact of basis set superposition error on the structure of $\pi-\pi$ dimers. Int J Quantum Chem 111:1893-1901

73. Granatier J, Lazar P, Otyepka M, Hobza P (2011) The nature of the binding of $\mathrm{Au}, \mathrm{Ag}$, and $\mathrm{Pd}$ to benzene, coronene, and graphene: from benchmark $\operatorname{CCSD}(\mathrm{T})$ calculations to plane-wave DFT calculations. J Chem Theory Comput 7:3743-3755

74. Mansell SM, Russell CA, Wass DF (2008) Synthesis and structural characterization of tin analogues of N-heterocyclic carbenes. Inorg Chem 47:11367-11375

75. Takatani T, Sherrill CD (2007) Performance of spin-componentscaled Møller-Plesset theory (SCS-MP2) for potential energy curves of noncovalent interactions. Phys Chem Chem Phys 9: 6106-6114

76. Bühl M, Kabrede H (2006) Geometries of transition-metal complexes from density-functional theory. J Chem Theory Comput 2:12821290

77. Furche F, Perdew JP (2006) The performance of semilocal and hybrid density functionals in $3 \mathrm{~d}$ transition-metal chemistry. J Chem Phys 124:044103

78. Chan B, Ball GE (2013) A benchmark ab initio and DFT study of the structure and binding of methane in the $\sigma$-alkane complex $\mathrm{CpRe}(\mathrm{CO})_{2}\left(\mathrm{CH}_{4}\right)$. J Chem Theory Comput 9:2199-2208

79. Weymuth T, Couzijn EPA, Chen P, Reiher M (2014) New benchmark set of transition-metal coordination reactions for the assessment of density functionals. J Chem Theory Comput 10:3092-3103

80. Lee C, Yang W, Parr RG (1988) Development of the Colle-Salvetti correlation-energy formula into a functional of the electron density. Phys Rev B 37:785-789 
81. Zhao S, Li Z-H, Wang W-N, Liu Z-P, Fana K-N, Xie Y, Schaefer HF III (2006) Is the uniform electron gas limit important for small Ag clusters? Assessment of different density functionals for $\mathrm{Ag}_{\mathrm{n}}(\mathrm{n}=<$ 4). J Chem Phys 124:184102

82. Sierraalta A, Añez R, Alejos P (2013) Performance of density functional methods. Some difficult cases for small systems containing $\mathrm{Cu}$, Ag, or Au. J Phys Chem A 117:2619-2628

83. Muniz-Miranda F, Menziani MC, Pedone A (2014) Assessment of exchange-correlation functionals in reproducing the structure and optical gap of organic-protected gold nanoclusters. J Phys Chem C 118: 7532-7544

84. Paier J, Marsman M, Kresse G (2007) Why does the B3LYP hybrid functional fail for metals? J Chem Phys 127:024103

85. Perdew JP, Schmidt K (2001) Jacob's ladder of density functional approximations for the exchange-correlation energy. In: AIP Conf. Proc., pp 1-20

86. Shil S, Bhattacharya D, Sarkar S, Misra A (2013) Performance of the widely used Minnesota density functionals for the prediction of heat of formations, ionization potentials of some benchmarked first row transition metal complexes. J Phys Chem A 117:4945-4955

87. Cervantes-Navarro F, Glossman-Mitnik D (2013) The indigo molecule revisited again: assessment of the Minnesota family of density functionals for the prediction of its maximum absorption wavelengths in various solvents. J Chem: 153126

88. Zahn S, MacFarlaneb DR, Izgorodina EI (2013) Assessment of KohnSham density functional theory and Møller-Plesset perturbation theory for ionic liquids. Phys Chem Chem Phys 15:13664-13675

89. Mardirossian N, Lambrecht DS, McCaslin L, Xantheas SS, HeadGordon M (2013) The performance of density functionals for sulfate -water clusters. J Chem Theory Comput 9:1368-1380
90. Seth M, Ziegler T, Steinmetz M, Grimme S (2013) Modeling transition metal reactions with range-separated functionals. J Chem Theory Comput 9:2286-2299

91. Matczak P, Łukomska M (2014) Assessment of various density functionals for intermolecular $\mathrm{N} \rightarrow \mathrm{Sn}$ interactions: the test case of trimethyltin cyanide dimer. Comput Theoret Chem 1036:31-43

92. Becke AD (1988) Density-functional exchange-energy approximation with correct asymptotic behavior. Phys Rev A 38: 3098-3100

93. Perdew JP (1986) Density-functional approximation for the correlation energy of the inhomogeneous electron gas. Phys Rev B 33: 8822-8824

94. Perdew JP, Tao J, Staroverov VN, Scuseria GE (2003) Climbing the density functional ladder: nonempirical meta-generalized gradient approximation designed for molecules and solids. Phys Rev Lett 91:146401

95. Becke AD (1993) Density-functional thermochemistry. III. The role of exact exchange. J Chem Phys 98:5648-5652

96. Hertwig RH, Koch W (1997) On the parameterization of the local correlation functional. What is Becke-3-LYP? Chem Phys Lett 268: 345-351

97. Schmider HL, Becke AD (1998) Optimized density functionals from the extended G2 test set. J Chem Phys 108:9624-9631

98. Staroverov VN, Scuseria GE, Tao J, Perdew JP (2003) Comparative assessment of a new nonempirical density functional: molecules and hydrogen-bonded complexes. J Chem Phys 119:12129-12137

99. Peverati R, Truhlar DG (2011) Improving the accuracy of hybrid meta-GGA density functionals by range separation. J Phys Chem Lett 2:2810-2817 